Review

\title{
Natural compounds for cancer treatment and prevention
}

\author{
Stefania Nobili ${ }^{\mathrm{a}}$, Donatella Lippi ${ }^{\mathrm{b}}$, Ewa Witort ${ }^{\mathrm{c}, \mathrm{d}, * *}$, Martino Donnini $^{\mathrm{c}, \mathrm{d}, \mathrm{e}}$, \\ Letizia Bausi $^{c}$, Enrico Mini ${ }^{\mathrm{a}, *}$, Sergio Capaccioli ${ }^{\mathrm{c}, \mathrm{d}, \mathrm{e}}$
}

a Department of Pharmacology, University of Florence, Florence, Italy

b Department of Anatomy, Histology and Forensic Medicine, University of Florence, Florence, Italy

${ }^{\mathrm{c}}$ Department of Experimental Pathology and Oncology, University of Florence, Florence, Italy

${ }^{\mathrm{d}}$ Apoptosis Deregulation in Cancer Unit of Istituto Toscano Tumori (ITT), Florence, Italy

e Phoenix Stem Cell Foundation for Human Life (ONLUS), Florence, Italy

\section{A R T I C L E I N F O}

\section{Article history:}

Received 27 November 2008

Received in revised form 29 January 2009

Accepted 30 January 2009

\section{Keywords:}

Cancer

Natural compounds

Cancer therapy

Cancer chemoprevention

\begin{abstract}
A B S T R A C T
We describe here the main natural compounds used in cancer therapy and prevention, the historical aspects of their application and pharmacognosy. Two major applications of these compounds are described: as cancer therapeutics and as chemopreventive compounds. Both natural compounds, extracted from plants or animals or produced by microbes (antibiotics), and synthetic compounds, derived from natural prototype structures, are being used. We also focus on the molecular aspects of interactions with their recognized cellular targets, from DNA to microtubules. Some critical aspects of current cancer chemotherapy are also discussed, focusing on genetics and genomics, and the recent revolutionary theory of cancer: aneuploidy as the primum movens of cancer.
\end{abstract}

(C) 2009 Elsevier Ltd. All rights reserved.

\section{Contents}

1. Introduction ....

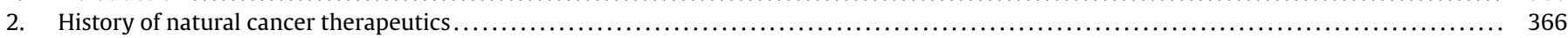

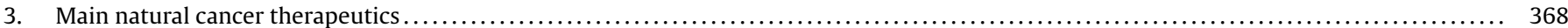

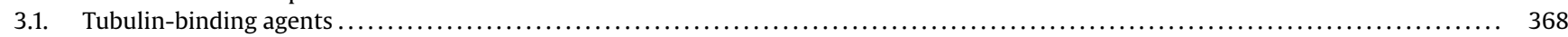

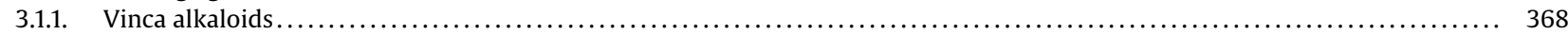

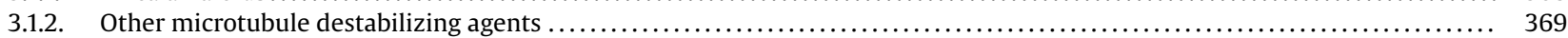

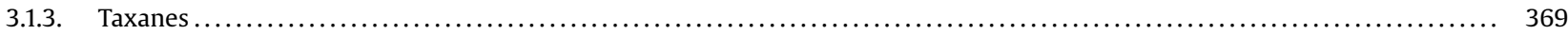

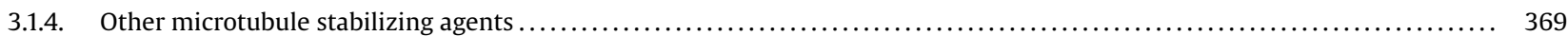

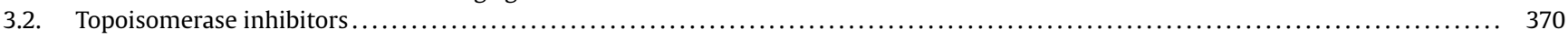

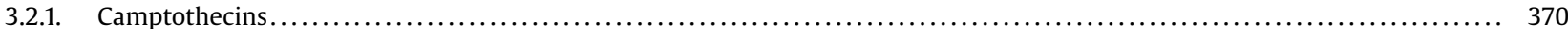

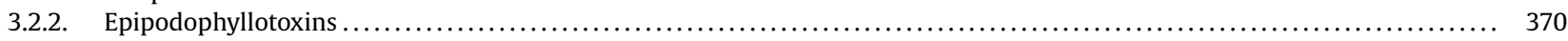

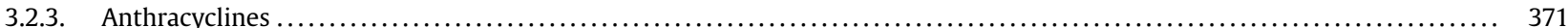

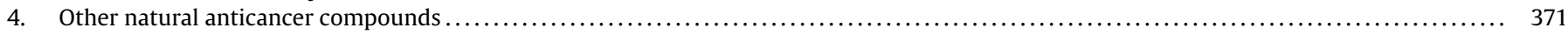

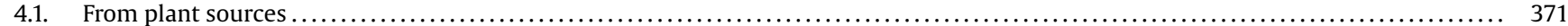

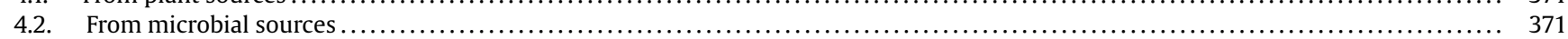

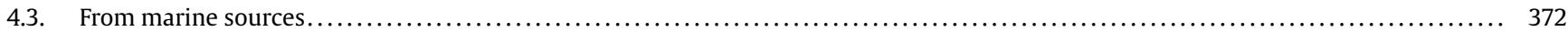

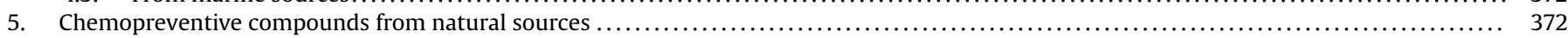

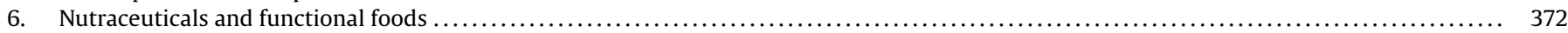

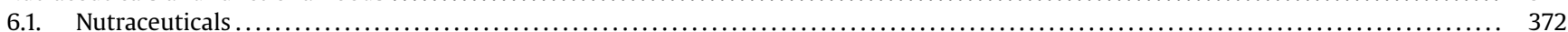

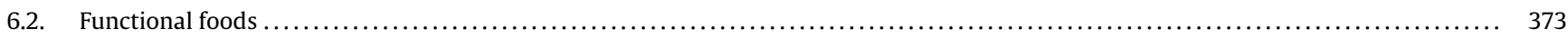

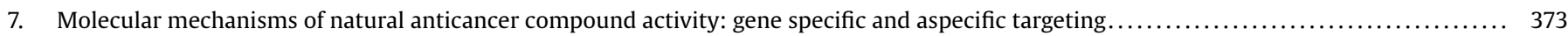

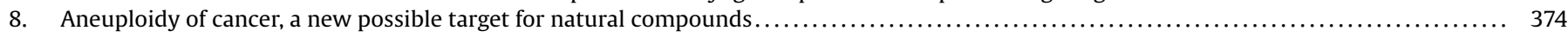

\footnotetext{
* Corresponding author at: Department of Pharmacology, University of Florence V.le Pieraccini, 6-50139 Firenze, Italy. Tel.: +39 0554271305 ; fax: +39 0554271280. ** Co-corresponding author at: Department of Experimental Pathology and Oncology, University of Florence, V.le G.B. Morgagni, 50-50134 Firenze, Italy. Tel.: +39055 4598208 .

E-mail addresses: enrico.mini@unifi.it (E. Mini), ewa@witort.com (E. Witort).
} 


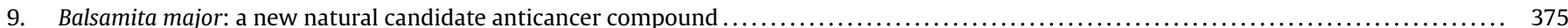

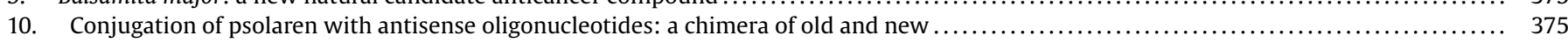

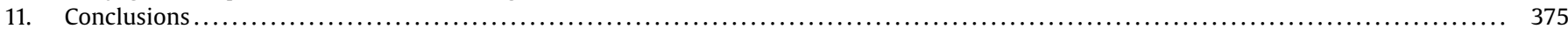

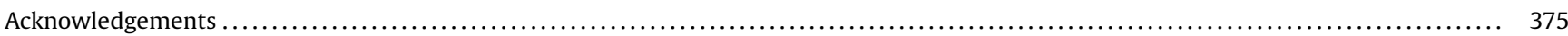

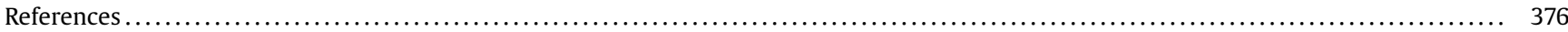

\section{Introduction}

There is evidence of cancer found in ancient human remains and in the medical literature since antiquity, dating back to the times of the Pharaohs in ancient Egypt and the classical world. Although it is difficult to interpret the diagnosis of physicians who lived so many centuries ago, we can assume that many of their descriptions related to cases of cancer.

The ancient medical literature reports that surgery was performed but that physicians also recommended the use of some natural, and especially plant products, which represent an interesting point of comparison with current knowledge. Natural products play a relevant role in cancer therapy today with substantial numbers of anticancer agents used in the clinic being either natural or derived from natural products from various sources such as plants, animals and microorganisms (also of marine origin) (Fig. 1). Large-scale anticancer drug discovery and screening programs such as those promoted by the National Cancer Institute $(\mathrm{NCI})$ have played an important role in the development of anticancer natural compounds. During the last few years, natural-product-based drug discovery is increasing based on new technologies, such as combinatorial synthesis and high-throughput screening, and their associated approaches. Vincristine, irinotecan, etoposide and paclitaxel are classic examples of plant-derived compounds; actinomycin D, mitomycin C, bleomycin, doxorubicin and L-asparaginase are drugs coming from microbial sources, and citarabine is the first drug originating from a marine source. To date, new generations of taxanes, anthracyclines, Vinca alkaloids, camptothecins, as well as the novel class of epothilones have been developed. Some of these are in clinical use, others in clinical trials. Other agents originating from marine sources (both plants and animals) (e.g. trabectedin-ET-743, bryostatin-1, neovastat) have also entered clinical trials. All these drugs are characterized by a variety of different mechanisms of action including for example interaction with microtubules, inhibition of topoisomerases I or II, alkylation of DNA, and interference with tumour signal transduction.

This review describes the main natural compounds used in cancer therapy and prevention. Within the framework of their historical aspects and pharmacognosy, which is the study of their natural producers, plants, animals, and microorganisms, and their chemical composition, a variety of paradigmatic natural compounds are described. These aspects are integrated and updated by also focusing on the most recent knowledge of the molecular aspects of interactions with their recognized cellular targets, from DNA to microtubules. Some critical aspects of current cancer chemotherapy are also pointed out, as well as that of a recent revolutionary theory of cancer: whereby not cancer gene mutations but caretaker genes and/or aneuploidy are the primum movens of cancer.

\section{History of natural cancer therapeutics}

The use of botanicals - plants, herbs, fungi, seeds - as medicines predates recorded history and represents the most significant direct antecedent to modern medicine. In recent times, some of the most encouraging clinical evidence of the value of herbs in treating cancer permits us to reconstruct the story of these plants and their eventual use in these cases. First of all, it is important to remember that the modern concept of cancer is very different from the ancient one: the word cancer derives from the father of medicine, Hippocrates, who used the Greek word Karkinos to describe tumours, but the history of cancer actually begins much earlier. It is difficult to identify the diagnosis of cancer in ancient texts, just from the literary description. Progress in understanding and treating cancer has been slow and based on the development of pathological anatomy, starting from the 18th century. The last 50 years have seen an explosion in our understanding of this most fundamental of diseases, and new discoveries occur on an almost weekly basis. For this reason, it is possible to find evidence of the relationship between botanicals and cancer only in recent times [1]. Some of the many botanical compounds, which have been demonstrated to have positive effects in cancer therapy, have a long history behind them. For example, it was recently demonstrated that the green tea antioxidant EGCG (epigallocatechin-3-gallate) significantly slowed breast cancer growth in female mice: its use is attested in ancient Japanese texts.

Promising and selective anti-cancer effects have been observed with Saffron (stigmata of Crocus sativus L.) in vitro and in vivo, but not yet in clinical trials [2-3]. The search for anticancer lead compounds has been the mainstream of marine chemistry. As a result, a number of natural marine products with unique mechanisms of action have been identified and recently entered into clinical trials [4-5].

The use of juice, peel and oil of Punica granatum has also been shown to possess anticancer activity, including interference with tumour cell proliferation, cell cycle, invasion and angiogenesis [6]. Modern scientific research has revealed that the wide variety of dietary and medicinal functions of garlic can be attributed to the sulfur compounds present in or generated from garlic, which can have an effective anticancer effect [7]. Myrrh is derived from the dried resin of desert trees, Commiphora myrrha and other species. In biblical terms, it was chosen, along with frankincense and gold, as a gift of the Three Wise Men to the newborn Christ. Hailed for its anti-inflammatory and disinfectant properties, myrrh has historically been used for ailments as diverse as stomach pain, indigestion, poor circulation, wound healing, certain skin diseases and irregular menstrual cycles. What makes myrrh such an exciting player in the anti-cancer field is not only how well it kills cancer cells in general, but how it kills those that are resistant to other anti-cancer drugs. It is believed to work by inactivating a protein called $\mathrm{Bcl}-2$, a natural factor that is overproduced by cancer cells, particularly in the breast and prostate. Although myrrh compound does not appear to be as powerful as other anti-cancer drugs derived from plants - such as, vincristine, vinblastine and paclitaxel - its advantage seems to lie in the fact that it can harm cancer cells without harming healthy cells, something these other drugs do not do [8].

One of the most significant plant compounds in the fight against cancer was discovered in the bark, and at low levels in the needles, of the relatively rare Pacific Yew, Taxus brevifolia. In the 1970s, the $\mathrm{NCI}$ tested plants in a number of collections, including an extract from the Pacific Yew collected by the U.S. Department of Agriculture in 1962. They discovered taxol, now named paclitaxel, which has become one of the most effective drugs against breast and ovarian cancer and has been approved worldwide for the clinical treatment of cancer patients. Hailed as having provided one of the most significant advances in cancer therapy, paclitaxel exerts its anticancer activity by inhibiting mitosis. Since harvesting the bark kills the tree and still does not provide enough paclitaxel for the tens of thousands of cancer patients needing this treatment, 
(A)

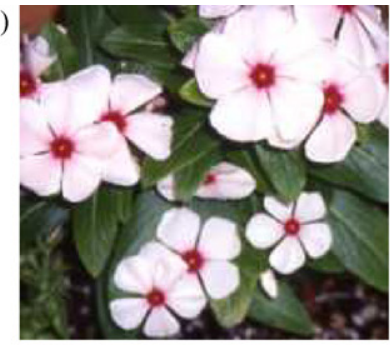

Chataranthus roseus (Vinca rosea)

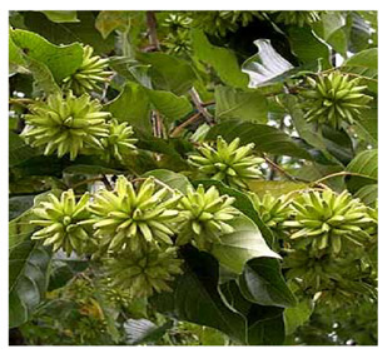

Camptotheca acuminata

(B)

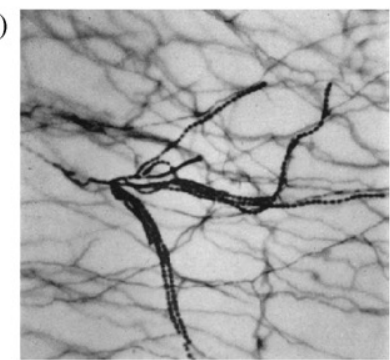

Actinomyces antibioticus

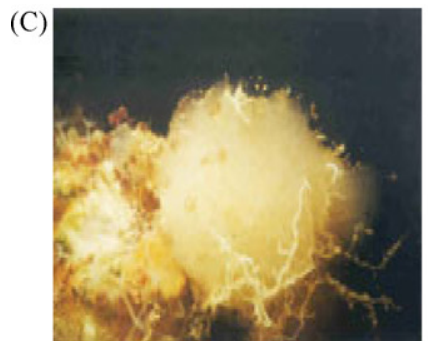

Aplidium albicans

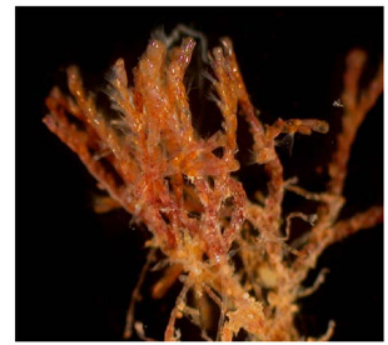

Bugula neritina

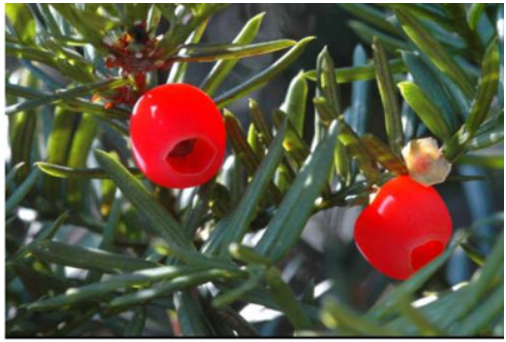

Taxus brevifolia

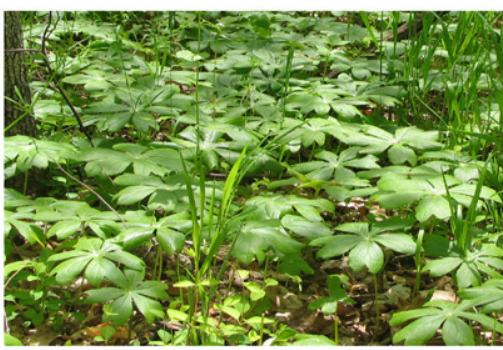

Podophyllum peltatum

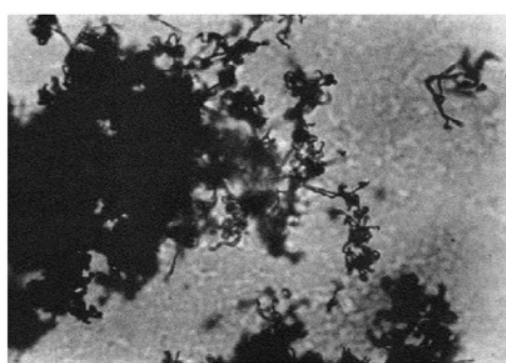

Streptomyces peucetius var. caesius

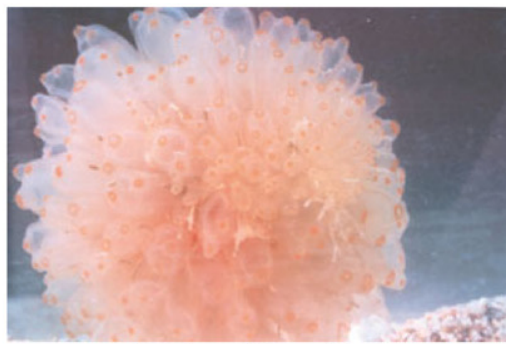

Ecteinascidia turbinata

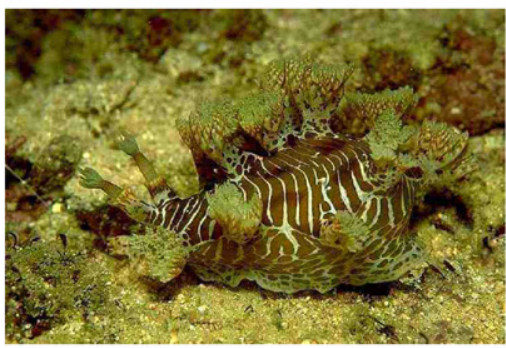

Dolabella auricularia

Fig. 1. Main examples of plant (A) microbial (B) and marine (C) sources of anticancer agents.

chemists have successfully worked to synthesize the compound from simpler structures. In 1990, Robert A. Holton developed the chemistry to synthesize paclitaxel from 10-deacetyl baccatin III extracted from the needles of the English Yew shrub which is also common in Europe and the United States, thus avoiding the destruction of the environment through the harvest of yew trees [9]. Later on, the same group of researchers published the first total synthesis of paclitaxel [10]. The first clinical trials with paclitaxel were car- ried out in 1983 and by 1988 preliminary data showed impressive results in patients with ovarian cancer. In the early studies involving patients with progressive disease, more than 30\% experienced tumour shrinkage and at least half of those had a response that lasted longer than a year. This gave rise to the development of an extensive and successful program of clinical trials in ovarian and breast cancer. The current focus of interest afterward moved to the development of improved analogues of this drug [11]. 
The discovery of the first antibacterial agents in the 1920-1940s also led to an intense research for anticancer agents from microorganisms.

The discovery of the first anti-tumoural antibiotic was made by Selman Waksman and H. Boyd Woodruff who in 1940 isolated actinomycin D from Actinomyces antibioticus [12]. This compound, a chromo-oligopeptide that acts as an inhibitor of RNA polymerase, is a member of a group of antibiotics (actinomycins) prevalently characterized by antibacterial activity and all discovered by the same research group at Rutgers University. Farber et al. [13] and Keidan [14], described the clinical anti-tumoural activity of actinomycin $D$ in a number of childhood tumours including metastatic Wilms's tumours.

The study of anthracycline glycosides and their aglicones isolated from different Streptomyces species, began in the 1950s and achieved extremely relevant results when, in the early 1960s, a compound named daunomycin (also known as daunorubicin) with antileukaemic properties was isolated from a strain of Streptomyces peucetius, var. caesius by Di Marco and co-workers [15]. The 14hydroxy derivate of daunorubicin (i.e. adriamycin), also produced by Streptomyces peucetius and related strains, was isolated in 1969 by Arcamone et al. [16] at the Farmitalia Research Laboratories. The name of this compound (today known as doxorubicin) derives from the Adriatic Sea near which the original daunorubicin strain had been collected.

In addition to the above described terrestrial sources for anticancer agents, a still almost completely unexplored potential source is represented by the sea. Although oceans have attracted the attention of researchers since the 1950s with the discovery of the Cryptotheca crypta sponge-derived nucleosides spongothymidine and spongouridine [17], the technical difficulties of collecting marine organisms together with the poor knowledge of this habitat have posed a relevant obstacle. The implementation of scuba diving tools and the development of instruments for the isolation of natural products from marine organisms have allowed the identification of a great number of marine compounds (over 16,000) but only a few of these have gone though preclinical and clinical evaluation.

The history of marine anticancer agents officially starts in 1960 when cytarabine, a pyrimidine nucleoside analogue, was developed on the basis of the two above reported sponge-derived nucleosides [18]. This drug showed anticancer efficacy in leukaemias and lymphomas. The use of cytarabine has nowadays been rejuvenated by the introduction in the clinic of a liposomal formulation indicated for the intrathecal treatment of lymphomatous meningitis.

In the same years bryostatins, a group of macrolide lactones, were isolated from the bryozoan species Bugula neritina. In 1970 Dolastatin 10 was isolated from the mollusc Dolabella auricularia living in the Indian Ocean; it failed to show anti-tumour efficacy but offered a basis for structure activity relationship studies (e.g. synthesis of TZT-1027, soblidotin). From then on, a variety of other marine anticancer compounds or their semisynthetic or synthetic derivatives have undergone the clinical investigation. Such compounds include halicondrins and didemnins isolated in the 1980s and characterized by classical cytotoxic mechanisms of action, as well as compounds isolated from the end of 1990s and characterized by more intriguing mechanisms of action (e.g. salinosporamide that inhibits proteasome or neovastat that blocks the vascular endothelial growth factor (VEGF) binding to its receptor) $[19,20]$.

\section{Main natural cancer therapeutics}

\subsection{Tubulin-binding agents}

Soluble tubulin is a heterodimer of one molecule of $\alpha$-tubulin and one molecule of $\beta$-tubulin. To date, six isotypes of $\alpha$-tubulin and seven of $\beta$-tubulin are known [21]. During polymerization, the heterodimers link together to form protofilaments. Thirteen of these protofilaments organized in a hollow cylinder make up the backbone of the microtubule [22]. Microtubules are in dynamic equilibrium with tubulin heterodimers. This equilibrium, that is under the control of several factors, including microtubuleassociated proteins (MAPs) [23], is the target for microtubuledisrupting agents.

Microtubules are essential components of the cell cytoskeleton and are involved in a number of cellular functions. They are critical to the movement of organelles during interphase and during mitosis, form the mitotic spindle that transports daughter chromosomes to separate poles of the dividing cell. Drugs that interfere with microtubule function lead to failure of alignment of the daughter chromosomes and their bipolar attachment to the mitotic spindle; this effect leads to mitotic arrest at the metaphase/anaphase transition, followed by apoptosis [22]. This has been suggested as the primary anti-neoplastic mechanism of action of tubulin-binding drugs although it has also been postulated that at least part of the anti-tumour effect of these agents is related to their effect on microtubules in interphase cells. Vinca alkaloids and taxanes represent the main classes of tubulin-binding agents.

\subsubsection{Vinca alkaloids}

Vinca alkaloids are isolated from the periwinkle plant Catharanthus roseus, also known as Vinca rosea. Extracts of Vinca rosea possess many therapeutic effects including anti-tumour activity. Vincristine, vinblastine and vindesine are the first vinca alkaloids with anti-tumour activity to be identified. Vinorelbine is the first new second-generation vinca alkaloid to emerge from structural modification studies in the velbanamine or "upper" portion of the vinblastine structure [24]. Vinflunine, a bis-fluorinated vinorelbine derivative, has been synthesized by superacid chemistry [24]. Due to its favourable preclinical anti-tumour activities, including microtubule dynamics disruption, antiangiogenesis and prolonged multidrug resistance development, vinflunine is now being widely studied in phase I-III clinical trials [25].

The vinca alkaloids are dimeric asymmetrical compounds consisting of two multi-ringed subunits, vindoline and catharantine, linked by a carbon-carbon bridge.

Vinca alkaloids disrupt the mitotic spindle assembly through interaction with tubulin. In particular, they bind specifically to $\beta$ tubulin and block its ability to polymerize with $\alpha$-tubulin into microtubules. This leads to the killing of actively dividing cells by inhibiting progression through mitosis. However, newer vinca alkaloids, such as vinorelbine and vinflunine, have proved to be weak binders in contrast to with the strong binding of vincristine and the intermediate level of vinblastine. Evidence indicates that vinorelbine and vinflunine affect microtubule dynamics differently from vinblastine [26].

The most widely recognized mechanism of resistance to vinca alkaloids is due to the multidrug resistance-associated $\mathrm{P}$ glycoprotein (P-gp) [27] and the multidrug resistance protein (MRP) [28]. The overexpression of these two proteins belonging to the ATPbinding cassette $(A B C)$ transporter family has been associated with reduced intracellular accumulation of vinca alkaloids and corresponding reduction in cytotoxicity. Bcl-XL and Bcl-2 overexpression protect vincristine and vinblastine in the absence of P-gp or other drug resistance associated genes [29,30].

Vinca alkaloids are most commonly administered weekly by short IV injection (1-15 min), more rarely by continuous infusion. Vinorelbine is the sole alkaloid available orally and it is administered as a single dose weekly [31].

Classical vinca alkaloids are largely used in the treatment of haematological and lymphatic neoplasms (especially vincristine) as well as in several solid tumours (e.g. vinblastine in breast, testicular cancer, choriocarcinoma; vindesine in non-small cell lung 
cancer, breast cancer, etc.). The newer drugs are mostly used in solid tumours, such as lung, breast and ovarian cancers. Side effects common to these drugs are myelosuppression and neurotoxicity.

Vinorelbine is used for the treatment of non-small cell lung cancer and metastatic breast cancer. The main toxic effect of vinorelbine is granulocytopenia with only modest thrombocytopenia and less neurotoxicity than other vinca alkaloids [32]. Vinflunine has been used in the treatment of bladder, non-small cell lung and breast cancers; its main side effects are myelosuppression and constipation which are apparently more manageable compared to the other vinca alkaloids [25].

\subsubsection{Other microtubule destabilizing agents}

The cryptophycins are a unique family of 16-membered macrolide antimitotic agents isolated from the cyanobacteria Nostoc sp. whose molecular target is tubulin protein. They are extremely potent suppressors of microtubule dynamics by slowing it in a concentration-dependent manner and depolymerizing microtubules in an irreversible way probably due to covalent drug-target interaction. In addition, they deactivate the Bcl-2 protein and produce an apoptotic response much more quickly and at considerably lower concentrations than clinically utilized compounds. The presence of several amide and ester linkages within the cryptophycin core provides access to very convergent total synthetic approaches. However, the in vivo hydrolytic instability of the C5 ester was a key obstacle to finding a clinical candidate. This problem has been somewhat ameliorated in the totally synthesized Cryptophycin- 52 by increased substitution at $\mathrm{C} 6$ as in the presence of gem-dimethyl substitution [33]. Despite the initial enthusiasm deriving from the possibility that cryptophycins would be able to overcome multidrug drug resistance in experimental systems, this occurrence has not been confirmed in clinical trials. In addition, Cryptophycin 52 showed only modest activity in patients with platinum-resistant advanced ovarian cancer [34].

Dolastatins are peptides originally isolated from the marine mollusc Dolabella auricularia. They inhibit microtubule assembly and tubulin polymerization. The pentapeptide dolastatin-10 was the most promising natural dolastatin agent. However, while its toxicity profile was acceptable, only minimal activity was observed in phase II studies performed in a variety of solid tumours [35-37]. A synthetic derivative of dolastatin-10, TZT-1027, seems to possess a good safety profile and some anti-tumour activity as reported in a phase I trial [38].

Halicondrins, in particular halichondrin B, were first isolated from the Japanese sponge Halichondria okadai. They are potent tubulin inhibitors that non-competitively bind to the Vinca binding site [39]. The synthetic macrocyclic ketone derivative of halichondrin B, eribulin (E7389), is characterized by enhanced anti-tumour activity compared to halichondrin B and is currently in phase III breast cancer clinical trials [40].

\subsubsection{Taxanes}

As reported in Section 2, paclitaxel, initially extracted from the bark of Taxus brevifolia [41], is now obtained by semisynthesis from 10-deacetylbaccatin III, which is extracted from the needles of the European yew tree, Taxus baccata. Docetaxel, a semisynthetic taxane with anticancer activity was directly obtained from 10-deacetylbaccatin III.

With the aim of ameliorating the tolerability of taxanes and reducing clinical resistance, many efforts have been made to find new taxane formulations (e.g. albumin, nanoparticles, emulsions, liposomes, polyglutamates) or new taxane analogues and prodrugs including orally bioavailable compounds $[42,43]$.

Compounds such as abraxane, CT-2103, docosahexenoic acid (DHA)-paclitaxel, are examples of new taxanes that have shown higher activity than paclitaxel in taxane-resistant cancers, as well as in tumours that have been unresponsive to paclitaxel. In addition, compared to the prototype, they have a safer toxicological profile and their administration does not require pre-medication for hypersensitivity reactions [44].

Paclitaxel and docetaxel are hydrophobic compounds characterized by a taxane ring core, estherification at the $\mathrm{C}-13$ position with a complex ester group, and an unusual fourth ring at the $C-4,5$ position. The last two structural features are essential for their biological activity [45]. Docetaxel differs from paclitaxel in terms of only two moiety groups [46].

Due to the poor solubility of these drugs, they are administered in formulations including two different polyoxyethylated surfactants. Since both solvents are biologically and pharmacologically active, they lead to adverse effects such as hypersensitivity reactions [47], peripheral neuropathies [48] or pharmacokinetic alterations especially for paclitaxel [49].

Taxanes exhibit unique cytotoxic activity by stabilizing microtubules rather than destabilizing them as vinca alkaloids do. In particular they promote the assembly of microtubules and prevent their depolymerization, thus interfering with a number of normal cellular functions that depend on the physiological balance between tubulin and microtubules [50,51].

Both paclitaxel and docetaxel bind to the 3-subunit of tubulin, rather than to tubulin dimers, and they bind to a specific site which is different from the binding site of guanosine triphosphate, colchicine, vinblastine, and podophyllotoxin [52,53].

Docetaxel has a 1.9-fold higher affinity for the site than paclitaxel, and induces tubulin polymerization at a 2.1 -fold lower critical tubulin concentration.

Paclitaxel and docetaxel have a different effect on the cell cycle. Paclitaxel inhibits the cell-cycle traverse at the G2-M phase junction [54] while docetaxel produces its maximum cell-killing effect against cells in the $S$ phase [55].

Other potential anti-tumour effects of taxanes not directly associated with the classical anti-microtubule action have been reported. The apoptosis induced by paclitaxel and docetaxel has also been associated with enhanced phosphorylation of Bcl-2 [56]. In addition, paclitaxel induces the release of tumour necrosis factor$\alpha$ (TNF- $\alpha$ ) and a decrease in expression of TNF receptors [57].

The mechanisms of resistance to taxanes are not fully understood and are likely to be multifactorial, including the overexpression of the membrane efflux pump P-gp [27], the presence of $\alpha$ and $\beta$ tubulin mutations, increased microtubule dynamics associated with altered microtubule-associated protein (MAP) expression [58]. Moreover, functional aberrations in multiple molecular pathways, such as cell cycle control, growth promotion and apoptosis can all contribute to taxane resistance [58].

No cross-resistance between paclitaxel and docetaxel has been observed in several in vitro and in vivo studies in cell lines made resistant to paclitaxel [59] and this observation has been somewhat confirmed in clinical trials [60].

Paclitaxel and docetaxel have very high activity in a spectrum of solid tumours (ovarian, breast, lung, head and neck, gastrooesophageal, bladder, testis, endometrium neoplasms) and in some haematological and paediatric malignancies [61,62]. Both drugs are active as single agents and in combination chemotherapy.

The clinical success of taxanes has been accompanied by significant side effects such as neutropenia, mucositis, hypersensitivity reactions and neuropathy. The latter two are mainly due to the solvents used for solubilizing these drugs and are controlled or prevented by use of prophylactic medication. Peripheral neuropathy is less frequent and less severe for docetaxel than for paclitaxel.

\subsubsection{Other microtubule stabilizing agents}

A series of new agents derived from different biological sources have been identified. They include epothilones (from the soil- 
dwelling myxobacterium Sorangium cellulosum), discodermolide (from the Caribbean sponge Discodermia dissoluta), eleutherobin (from the soft coral Eleutherobia sp.), the sarcodictyins A-D (from the corals Sarecodictyon roseium and Eleutherobia aurea), laulimalide and isolaulimalide (from the marine sponge Cacospongia mycofijiensis).

These compounds have a common target and nearly identical binding sites. Some of these compounds compete with paclitaxel for binding to microtubules and appear to bind at or near the taxane site (epothilones, discodermolide, eleutherobin), but others, such as laulimalide, seem to bind to unique sites on microtubules.

All these agents possess either low level or no substrate affinity for P-gp and other ABC transporters, and retain various degrees of activity against taxane-resistant cells in vitro, but the clinical implications of these characteristics are not clear [44].

Among these compounds, epothilones are effective anticancer drugs for the treatment of breast cancer patients, including those who have been previously treated with or are resistant to anthracyclines or the taxanes. Epothilone A and B are natural products and several of their analogues have also been investigated in clinical trials. Ixabepilone is the first member of the epothilone family to be approved for clinical use. It is indicated for the treatment of metastatic breast cancer $[63,64]$.

Discodermolide has been the focus of intense research activity in order to develop a practical supply route, and these efforts ultimately allowed its large-scale synthesis and the initiation of clinical trials as a novel anticancer drug [65].

\subsection{Topoisomerase inhibitors}

The DNA topoisomerases are nuclear enzymes that reduce torsional stress in supercoiled DNA, allowing selected regions of DNA to become sufficiently untangled and relaxed to permit its replication, recombination, repair and transcription.

Inhibitors of topoisomerase I and II are anticancer drugs active in a variety of haematological and solid tumours. They exhibit different pharmacological properties as well as different pharmacokinetics and toxicological profiles [66,67].

The plant-derived camptothecins (irinotecan, topotecan) act as inhibitors of topoisomerase I; the plant-derived epopodophyllotoxins (etoposide and teniposide) and the microbial-derived anthracyclines (e.g. doxorubicin, epirubicin) act as inhibitors of topoisomerase II.

\subsubsection{Camptothecins}

In the 1950s, an extensive screening programme of the $\mathrm{NCI}$ led to the isolation of an extract of the Chinese tree Camptotheca acuminata characterized by cytotoxic activity against a variety of leukaemias and solid tumours. In 1966 campthotecin was identified as the active constituent of the extract [68]. Despite promising preclinical and clinical anti-tumour activity the use of the first camptothecin formulation was hindered by severe and unpredictable toxicity. After years of intense research, in 1996 two semisynthetic camptothecin analogues, irinotecan and topotecan, entered the clinics for the treatment of colorectal and ovarian cancer, respectively [69].

Today several synthetic camptothecin analogues are in various stages of clinical evaluation (e.g. lurtotecan, exatecan mesylate, karenitecin, gimatecan). They present some advantages compared to classical semisynthetic camptothecins. In particular, some of these are not a substrate for P-gp (gimatecan, exatecan) [66,70], and for the breast cancer resistance protein (BCRP) (gimatecan) [70]; karenitecin is a very lipophilic compound that might show potential clinical advantages by virtue of its increased lactone stability and enhanced oral bioavailability [71]. These agents are currently in phase I-II trials.
Camptothecin derivatives have a basic five-ring (A-E) structure with a chiral centre located at position 20 in the terminal lactone (E) ring [72,73]. The hydroxyl group and S-conformation of the chiral centre to which it is attached are absolute requirements for biological activity (the hydroxyl group is essential for cytotoxicity, the lactone ring for topoisomerase I targeting activity) [72,73].

Topotecan is a semisynthetic derivative of camptothecin with a basic $N, N$-dimethylaminomethyl functional group at C-9 that confers water solubility to the molecule. Irinotecan is a watersoluble prodrug designed to facilitate parental administration of the potent 7-ethyl-10-hydroxy analogue of camptothecin (SN-38). During the catalytic cycle, topoisomerase I binds covalently to double-stranded DNA through a reversible trans-estherification reaction. The trans-estherification reaction leads to the formation of covalent binding between topoisomerase I and DNA (cleavable complex) [73]. Camptothecins cause DNA damage by stabilizing the covalent topoisomerase I-DNA complex, thus preventing religation [74].

A variety of cellular mechanisms of resistance to camptothecins which may have relevance in the clinical setting have been described and widely reviewed [73,75]. ATP transporters such as Pgp, MRP and especially BCRP, are responsible for the cellular efflux of topotecan and irinotecan from tumour cells. Drug metabolism may also play a role in the resistance of tumours to the prodrug irinotecan, e.g. the reduced expression of the carboxylesteraseconverting enzyme that generates the active SN-38 metabolite or the increased inactivation of SN-38 by catabolism to SN-38 glucuronide.

Other mechanisms of resistance may involve the target enzyme, e.g. decreased expression or mutations of topoisomerase, posttranslational events, such as topoisomerase I phosphorylation or poly-ADP ribosylation.

Ubiquitin/26S proteasome-dependent degradation of topoisomerase I may also play a role in the repair response to topoisomerase I-mediated DNA damage. Nevertheless, it has been shown that cells without functional p53 can undergo apoptosis after exposure to camptothecins. Prolongation in the duration of the cell cycle has been associated with resistance to camptothecins, presumably by reducing the proportion of cells in S phase at any given time.

Topotecan is indicated in second-line therapy against advanced ovarian carcinoma in patients who have failed previous treatment with platinum compounds or paclitaxel-containing chemotherapy regimens [76]. The dose-limiting toxicity for topotecan is neutropenia, with or without thrombocytopenia [77]. The major therapeutic indication for irinotecan is the first-line treatment of metastatic colorectal cancer patients in combination with 5-FU [78], and recently also with the monoclonal antibody bevacizumab [79]. Encouraging results have also been reported in other types of solid tumours (e.g. small cell and non-small cell lung cancer, cervical, ovarian cancers). The dose-limiting toxicities are delayed diarrhoea and neutropenia [66]. A cholinergic syndrome resulting from inhibition of acetylcholinesterase activity by irinotecan also frequently occurs within the first $24 \mathrm{~h}$ after dosing [80].

\subsubsection{Epipodophyllotoxins}

Podophyllotoxins have a long therapeutic history. Extracted from the root of the Indian podophyllum plant (Podophyllum peltatum), podophyllotoxin was used as a remedy by the American Indians for its emetic, cathartic, and anthelminthic effects. From a wide program of chemical synthesis (about 600 derivatives from 1950s to 1960s), two active compounds, etoposide and teniposide, emerged. Unlike other podophyllotoxin derivatives, etoposide and teniposide have no effect on microtubular structure or function at concentrations used in the clinic [81]. 
Etoposide and teniposide are similar in their action and in their spectrum of human tumour activity. DNA topoisomerase II is the key cellular target for both etoposide and teniposide. Topoisomerase II is a nuclear enzyme which alters DNA tertiary structure by creating transient double-stranded breakage of the DNA backbone, thus allowing subsequent passage of a second intact DNA duplex through the break [82]. Etoposide and teniposide form a ternary complex with topoisomerase II and DNA and prevent resealing of the DNA break. During the presence of epipodophyllotoxins, the topoisomerase II-DNA intermediate cannot be reversed, resulting in DNA double strand-breaks leading to cell death. Both epipodophyllotoxins are substrates for membrane efflux pumps, including P-gp. Amplification of the mdr-1 gene that encodes Pgp, has been observed in epipodophyllotoxin-resistant cells. Clinical studies combining etoposide with non-cytotoxic substrates for P-gp (e.g. PSC 833) have been performed in attempts to circumvent this mechanism of drug resistance. Other mechanisms of resistance due to mutations or decreased expression of topoisomerase II have been described in epipodophyllotoxin-resistant cells [81]. Mutations of p53 have also been found to represent a mechanism of resistance in cell lines resistant to epipodophyllotoxins [83].

The approved indications for etoposide are lung cancer, choriocarcinoma, ovarian and testicular cancers, lymphoma and acute myeloid leukaemia.

Teniposide is approved for central nervous system tumours, malignant lymphoma, and bladder cancer [66].

Myelosuppression is a common adverse effect of etoposide; leucopoenia is the dose-limiting toxicity while thrombocytopenia occurs less often and usually is not severe. Gastrointestinal toxicities (nausea, vomiting, stomatitis, mucositis) occur in about $15 \%$ of patients treated with IV etoposide and in about 55\% treated with oral etoposide. Alopecia is common but reversible. Hypersensitivity reactions to both drugs have been observed $[84,85]$. However, these adverse effects are primarily due to the adjuvants used in the parenteral formulations, rather than to the drugs [66].

\subsubsection{Anthracyclines}

After daunorubicin and doxorubicin, a series of semisynthetic compounds (e.g. idarubicin, epirubicin) followed and entered clinical use. Today a series of new anthracycline formulations have been approved for use in the clinic (e.g. liposomal formulations) and new analogues fully synthesized anthracycline are in the advanced phases of clinical studies (e.g. sabarubicin, MEN 10755, nemorubicin). All anthracyclines share a quinonecontaining rigid planar aromatic ring structure (the chromophore) bound by an $O$-glycosidic bond to an aminosugar [86]. Several hundred structural analogues have been obtained by synthetic modification of daunorubicin or doxorubicin. The common quinone moiety in the anthracycline ring structure can readily participate in oxidation-reduction reactions that ultimately generate highly reactive chemical species thought to be responsible for anthracycline-induced cardiotoxicity. Thus small modifications, such as the different orientation of the C-4 hydroxyl group on the sugar in epirubicin compared to doxorubicin are able to reduce cardiotoxicity, preserving the anticancer activity [67].

Anthracyclines induce inhibition of topoisomerase II religation reaction, causing accumulation of protein-linked double and singlestrand DNA breaks (cleavable complex), which ultimately lead to cytotoxic DNA damage and cell death $[87,88]$. However, the precise steps by which anthracyclines stabilize DNA topoisomerase II $\alpha$ cleavage complex are not fully understood and may in fact be independent of DNA intercalation [89]. Anthracyclines are able to generate oxygen free radicals by at least two distinct pathways [90], but it is not clear if this contributes to cell death and antiproliferative effects. All anthracyclines are substrates for the P-gp-mediated drug efflux pump and the overexpression of P-gp represents a major mechanism of cellular resistance to these drugs [27]. Also MRP causes resistance to anthracyclines [91].

Drug resistance may also be due to gene mutations or downregulation of topoisomerase II [92]. Doxorubicin exhibits a broad spectrum of activity and remains one of the most effective anticancer drugs. It is widely used in the treatment of breast carcinoma, small cell lung cancer, ovarian carcinoma and lymphomas. Epirubicin has the same profile, but it is generally used in adult solid tumours rather than in other malignancies. Daunorubicin and idarubicin are mainly used for the treatment of adult and paediatric leukaemias, although they show activity also in lymphomas or breast cancer [86]. The side effects of doxorubicin and daunorubicin include bone marrow depression, stomatitis, alopecia and gastrointestinal and dermatological toxicity. Cardiac toxicity is a peculiar adverse effect observed with these agents. It is characterized by myocardial dysfunction and congestive heart failure. Epirubicin and idarubicin, that have been developed to improve therapeutic and pharmacological properties of the natural compounds, show reduced cardiotoxic effects.

\section{Other natural anticancer compounds}

\subsection{From plant sources}

Other examples of plant-derived compounds currently under investigation are flavopiridol, homoharringtonine, $\beta$-lapachone, combretastatin A4. Flavopiridol is a synthetic flavone derived from the plant alkaloid rohitukine, which was isolated from the leaves and stems of Amoora rohituka and later from Dysoxylum binectariferum [93]. Flavopiridol is a cyclin-dependent kinase inhibitor [94]. The agent is currently in phase I-II clinical trials [95,96]. Available evidence indicates encouraging response rates in a variety of solid and haematological malignancies and diarrhoea as the doselimiting toxicity. Based on in vitro synergy of flavopiridol with several conventional cytotoxic agents, combination clinical studies to evaluate flavopiridol with paclitaxel or cisplatin against advanced solid tumours are ongoing.

Homoharringtonine is an alkaloid isolated from the Chinese tree Cephalotaxus harringtonia [97]; it is characterized by efficacy against various leukaemias [98] and currently in phase II-III. The principal mechanism of action of homoharringtonine is the inhibition of protein synthesis, blocking cell-cycle progression [99].

$\beta$-lapachone is a quinone obtained from the bark of the lapacho tree (Tabebuia avellanedae). It is a DNA topoisomerase I inhibitor that induces cell-cycle delay at $G_{1}$ or $S$ (synthesis) phase before inducing either apoptotic or necrotic cell death in a variety of human carcinoma cells, including ovary, colon, lung, prostate and breast [100]. It is currently investigated in a phase I-II study [40].

Combretastatin A4, isolated from the stem wood of the South Africa tree Combretum caffreum, is a vascular disruptive agent. It inhibits tumour blood vessel growth, causing tumour cell death and necrosis. Phase I trials have shown some clinical activity of combretastatin A4 and a favourable toxicological profile [101].

\subsection{From microbial sources}

New compounds derived from microorganisms include rapamycin and geldanamycin. Rapamycin (sirolimus) is a macrolide compound obtained from Streptomyces hygroscopicus. Rapamycin is a potent immunosuppressant and also possesses antifungal and antineoplastic properties. Rapamycin acts as a specific inhibitor of m-TOR (mammalian target of rapamycin) that is a downstream mediator of PI3K/Akt [102]. Thus it selectively blocks transcriptional activation, leading to tumour cell growth and division. Geldanamycin, an analogue of rapamycin, is a benzoquinone 
ansamycin natural fermentation product from the same microbial source that binds to, and inhibits the $90 \mathrm{kDa}$ heat-shock protein HSP 90 [103]. In this way, it is also able to suppress the protein kinase activity of m-TOR [104]. Both agents are currently in phase I-II studies [40].

The tumour-inhibitory properties of the bacterial enzyme Lasparaginase were discovered more than 50 years ago $[105,106]$ and since then, L-asparaginases, have been used in the treatment of a variety of lymphoproliferative disorders and lymphomas, in particular acute lymphoblastic leukaemia, in combination with other anticancer agents, in children and in adults. The mechanism of action of L-asparaginase is represented by the depletion of asparagine, an amino acid essential to leukaemia cells, and by the subsequent inhibition of protein synthesis leading to cytotoxicity. Although L-asparaginase has been found in various plant and animal species, microorganisms are the most efficient and inexpensive sources of this enzyme. A variety of microbes including bacteria, fungi, yeast, actinomycetes and algae, produce L-asparaginase but that used in the clinic is from two bacterial species, viz. Escherichia coli and Erwinia caratovora. The efficacy of this drug is limited by the occurrence of hypersensitivity reactions and development of anti-asparaginase antibodies. In order to decrease the immunogenicity of the enzyme and to prolong its half-life, a form of $E$. coli L-asparaginase covalently linked to polyethylene glycol has been synthesized [107]. The pegylated form of asparaginase has been approved by the Food and Drug Administration (FDA). On July 2008, the European Medicines Agency (EMEA) recognized for pegylated $\mathrm{L}$-asparaginase the status of "orphan drug" and its use for the treatment of acute lymphoblastic leukaemia.

\subsection{From marine sources}

Marine compounds that have reached clinical investigation are trabectedin (or ET-743) isolated from Ecteinascidia turbinata, bryostatin, a macrolide lactone isolated from a species of bryozoan, Bugula neritina, kahalalide $\mathrm{F}$, a cyclodepsipeptide toxin isolated from the mollusc Elysia rubefescens, didemnin B isolated from Carribean tunicate, and the second generation didemnin aplidine isolated from Aplidium albicans. More recently also other compounds such as squalamine, isolated from the dogfish shark Squalus acanthias, LAF389, a synthetic analogue of bengamide B (a compound isolated from the Jaspis sponges of the coral reefs near the Fiji Islands and Australia), and neovastat, a derivative of shark cartilage extract have been developed to the stage of clinical trials.

Most of these compounds have been recognized by the FDA and the EMEA as "orphan drugs" for the treatment of various neoplasms.

Among the previously mentioned compounds, trabectedin has received the most extensive clinical investigation. It has shown clinical activity in a broad spectrum of solid tumours and in September 2007, EMEA granted its marketing authorization for the treatment of soft tissue sarcoma after failure of standard chemotherapy [108]. In addition positive results from a randomized phase III study comparing trabectedin with pegylated liposomal doxorubicin vs pegylated liposomal doxorubicin alone in ovarian cancer patients have been recently published [109].

These agents are characterized by different pharmacological properties. Although the exact mechanism of action of trabectedin is still not clearly defined, it is substantially a DNA and transcription interacting agent. This complex mechanism of action is due to the drug chemical structure comprised of three fused tetrahydroisoquinoline rings. Two of them bind covalently to the minor groove of DNA and the third protrudes out of the minor groove and may directly interact with transcription factors (e.g. SP-1) [110]. Various and conflicting reports about whether trabectedin is a substrate for P-gp have been published [27]. Bryostatin acts as a modulator of protein kinase $\mathrm{C}(\mathrm{PKC})$ activity, and enhances the effect of chemotherapeutic agents such as paclitaxel an inhibitor of PKC [111].

The mechanism of action of kahalalide $\mathrm{F}$ is not yet well elucidated; however, preliminary evidence suggests specific interactions with membranes or proteins. The agent is under evaluation in phase I-II studies for the treatment of solid tumours. The mechanism of action of didemnin B and aplidine involves several pathways, including cell cycle arrest, inhibition of protein synthesis and antiangiogenic activity. Aplidine is characterized by delayed neuromuscular toxicity that requires careful follow-up but displays promising anti-tumour activity. It is currently in phase I-II trials [20].

Compounds such as squalamine, LAF389 and neovastat have shown antiangiogenic activity. Targets of squalamine and LAF389 are the phospholipid bilayer by inhibition of the sodiumhydrogen antiporter sodium-proton exchangers and the methionine aminopeptidase, respectively. Neovastat inhibits the binding of VEGF to its receptor $[19,20]$.

LAF389 has been studied in a phase I trial [112]. Squalamine and neovastat are currently evaluated in phase II and III studies, respectively [40].

\section{Chemopreventive compounds from natural sources}

Chemoprevention is a promising anticancer approach aimed at reducing the morbidity and mortality of cancer by delaying the process of carcinogenesis. Curcumin is one of the most studied chemopreventive agents. It is a natural compound extracted from the rhizome of Curcuma longa L. that allows suppression, retardation or inversion of carcinogenesis. Curcumin has also been shown to possess anti-tumour activity in a variety of in vitro tumour models (cell lines from solid tumours and leukaemia) as well as in tumour animal models. Its particular toxicological profile (doses up to $8000 \mathrm{mg} /$ day are still safe) has allowed the development of a large number of phase II studies [113,114]. As chemopreventive agent, curcumin is currently in phase II studies in colorectal cancer patients [114].

Another candidate chemopreventive agent is resveratrol, a polyphenol found in numerous plant species, including mulberries, peanuts and grapes. Its potential chemopreventive and chemotherapeutic activities have been demonstrated in all three stages of carcinogenesis (initiation, promotion, and progression), in both chemically and UVB-induced skin carcinogenesis in mice, as well as in various murine models of human cancers. Evidence from numerous in vitro and in vivo studies have confirmed its ability to modulate various targets and signalling pathways [115]. As a chemopreventive agent, resveratrol is currently in phase I studies in colorectal cancer patients and in healthy subjects at high risk of developing melanoma [40].

\section{Nutraceuticals and functional foods}

\subsection{Nutraceuticals}

A nutraceutical is a product isolated or purified from foods that are generally sold in a medicinal form not usually associated with foods. The term initially arose by combining "nutrition" and "pharmaceutical", and was defined as a food that provided medical or health benefits. Nutraceutical has to be demonstrated to possess protective action against chronic diseases or to have physiological benefit. The concept generally refers to dietary supplements that contain a concentrated form of bioactive substance originally derived from food [116].

The examples of nutraceuticals with claimed benefits include resveratrol from red grape products as an antioxidant, soluble 
dietary fibre products such as psyllium seed husk for reducing hypercholesterolemia, sulforaphane from broccoli as a cancer preventive and isoflavonoids from soy or clover which improve arterial health. However, only the beneficial effect of psyllium as a fibre product has been sufficiently documented in human clinical trials to receive approval by the FDA for the health claim statements on its product labels.

Other nutraceuticals include flavonoid antioxidants, such as alpha-linolenic acid from flax seeds, beta-carotene from marigold petals, anthocyanins from berries. Several other compounds have been added to the list of dietary supplements mentioned by the FDA and many botanical and herbal extracts such as ginseng, garlic oil etc. have been developed.

Clinical therapeutic effects of nutraceuticals have been studied in large epidemiological studies and trials on the use of varying nutritional supplements to prevent cancer. The European Prospective Investigation into Cancer and Nutrition trial (EPIC) began in 1992 and is focused on identification of dietary determinants of cancer. This study has involved more the 520,000 participants in 10 countries and the preliminary data demonstrated a reduction in colorectal cancer with increased fibre intake [117].

Other nutraceuticals have been proposed as chemopreventive agents for colorectal cancer. Yellow mustard oil, which belongs to the Brassica family, has been reported to possess anticancer properties. The recent research by Prof Eskin's group at the University of Manitoba, Canada, demonstrated that mustard gum containing a complex mixture of extractable polysaccharides exerted a protective role in the development of colon cancer in preclinical rat models [118].

Bioactive plant compounds can interact with host cells, subsequently altering intracellular signal transduction pathways involving the transcription factors NF-kB, AP1 [119], and NF-E2related factor 2 (Nrf2) [120]. In particular, a dual role of Nrf2, either in chemoprevention or chemoresistance, has been recently recognized [120]. Chemopreventive compounds (e.g. sulforaphane, curcumin, resveratrol) are able to transcriptionally activate the Nrf2 target genes to trigger a cytoprotective response [121]. However, $\mathrm{Nrf} 2$ protects not only normal cells from transforming into cancer cells, but also promotes the survival of cancer cells in detrimental environments. Genetic alterations of the Nrf2 inhibitor Kelch-like $\mathrm{ECH}$-associated protein (Keap1) impair its ability to repress Nrf2 in cancer. The consequent increased transcription of Nrf2 downstream genes leads to increased expression of proteins (e.g. antioxidant and detoxicant enzymes, gene encoding transporters) that confers a growth advantage and drug resistance to cancer cells. [122]. These findings pose a relevant question on the use of Nrf2 activators as chemopreventive agents in patients where early steps of cancerogenesis might have been initiated as well as on the effects of their patient self-use in association to cancer chemotherapy.

\subsection{Functional foods}

A functional food is, or may be, similar in appearance to a conventional food that is consumed as part of a normal diet, but demonstrates physiological benefits and/or reduces the risk of chronic disease beyond basic nutritional functions and contains bioactive compounds. Some examples of functional food components obtained from the International Food Information Council are presented in Table 1.

Increasing numbers of people use dietary vegetables, medicinal herbs and plant extracts to prevent or treat cancer. The Indian system of medicine, named Ayurveda, leads the way in the use of natural compounds. Many plant products are in use as herbal medicinals, as food supplement or as spices in daily cooking. Some of them have been studied in various in vivo and in vitro experimental models of cancer, and have been shown to significantly
Table 1

Potential benefits of food supplementation with functional components from natural sources.

\begin{tabular}{|c|c|c|}
\hline Functional components & Source & Potential benefits \\
\hline Lycopene & Tomato products & $\begin{array}{l}\text { Reduces the risk of prostate } \\
\text { cancer }\end{array}$ \\
\hline Insoluble fibre & Wheat bran & $\begin{array}{l}\text { Reduces the risk of breast } \\
\text { or colon cancer }\end{array}$ \\
\hline Beta-glucan & Oats, barley & $\begin{array}{l}\text { Protects against heart } \\
\text { disease and some cancers }\end{array}$ \\
\hline Soluble fibre & Psyllium & $\begin{array}{l}\text { Protects against heart } \\
\text { disease and some cancers }\end{array}$ \\
\hline $\begin{array}{l}\text { Conjugated linoleic acid } \\
\text { (CLA) }\end{array}$ & $\begin{array}{l}\text { Cheese, meat } \\
\text { products }\end{array}$ & $\begin{array}{l}\text { Improves body } \\
\text { composition, decreases risk } \\
\text { of certain cancers }\end{array}$ \\
\hline Anthocyanidins & Fruits & $\begin{array}{l}\text { Neutralize free radicals, } \\
\text { reduce risk of cancer }\end{array}$ \\
\hline Catechins & Tea & $\begin{array}{l}\text { Neutralize free radicals, } \\
\text { reduce risk of cancer }\end{array}$ \\
\hline Flavonones & Citrus & $\begin{array}{l}\text { Neutralize free radicals, } \\
\text { reduce risk of cancer }\end{array}$ \\
\hline Flavones & Fruit/vegetables & $\begin{array}{l}\text { Neutralize free radicals, } \\
\text { reduce risk of cancer }\end{array}$ \\
\hline Lignans & Flax, rye, vegetables & $\begin{array}{l}\text { Prevention of cancer, renal } \\
\text { failure }\end{array}$ \\
\hline $\begin{array}{l}\text { Isoflavones: daidzein and } \\
\text { ganistein }\end{array}$ & $\begin{array}{l}\text { Soybeans and } \\
\text { soy-based foods }\end{array}$ & $\begin{array}{l}\text { Protect against some } \\
\text { cancer and heart disease }\end{array}$ \\
\hline
\end{tabular}

inhibit cancer cell proliferation [123,124]. An example of Ayurvedic supplement food is the Maharishi Amrit Kalash (MAK), an herbal formulation composed of two herbal mixtures, MAK-4 and MAK-5 with claimed potential to significantly inhibit the in vitro growth of cancer cells from human tumours [125]. Although these compounds were also able to inhibit the tumour progression in animal models [126], no reports of trials on these two herbal remedies in cancer patients are available at present. Many other herbs and spices such as turmeric (curcumin) and garlic are however being tested in clinical trials [40].

\section{Molecular mechanisms of natural anticancer compound activity: gene specific and aspecific targeting}

Throughout history, natural products have been a rich source of compounds that have found many applications in the fields of medicine, pharmacy and biology. In the cancer field, a number of important new commercialized drugs have been obtained from natural sources, by structural modification of natural compounds, or by the synthesis of new compounds, designed following a natural compound as model. The search for improved cytotoxic agents continues to be important in the discovery of modern anticancer drugs. The huge structural diversity of natural compounds and their bioactivity potential have meant that several products isolated from plants, marine flora and fauna, microorganisms can serve as lead compounds whereby their therapeutic potential is improved by molecular modification.

Additionally, semisynthetic processes of new compounds, obtained by molecular modification of the functional groups of lead compounds, are able to generate structural analogues with higher pharmacological activity and with fewer side effects. These processes, complemented with high-throughput screening protocols, combinatorial chemistry, computational chemistry and bioinformatics can provide compounds that are far more efficient than those currently used in clinical practice. Combinatorial biosynthesis is also applied for the modification of natural microbial products. Likewise, advances in genomics and the advent of biotechnology have improved both the discovery and production of new natural compounds.

DNA damage can induce apoptosis. Apoptosis is also widely believed to be the major anti-proliferative mechanism of DNA- 
damaging anticancer drugs. However, induction of apoptosis of carcinoma cells generally requires drug concentrations that are at least one order of magnitude higher than those required for loss of clonogenicity. This is true for different DNA-damaging drugs such as cisplatin, doxorubicin and camptothecin. Here, we discuss apoptosis induction by DNA-damaging agents using cisplatin as an example. Recent studies have shown that cisplatin induces caspase activation in enucleated cells (cytoplasts lacking a cell nucleus). Cisplatin-induced apoptosis in both cells and cytoplasts is associated with rapid induction of cellular reactive oxygen species and increases in $\mathrm{Ca}^{2+}$. Cisplatin has also been reported to induce clustering of Fas/CD95 in the plasma membrane. Available data suggest that the primary responses to cisplatin-induced DNA damage are induction of long-term growth arrest ("premature cell senescence") and mitotic catastrophe, whereas acute apoptosis may be due to “off-target effects" not necessarily involving DNA damage.

\section{Aneuploidy of cancer, a new possible target for natural compounds}

More then 200 years ago, the researchers studying microscopic images of human tumour cells noticed that these cells often contained excessive numbers of chromosomes. Instead, the normal cells found in surrounding stroma contained an invariable complement of 46 chromosomes. Subsequently, it was demonstrated that human cancer cells could possess between 60 and 90 chromosomes and that they differed from each other by the number of chromosomes they contained. Moreover, these chromosomes demonstrated structural aberrations: inversions, deletions, duplications and translocations. These numerical and structural abnormalities were defined as aneuploidy. Today, even after more than two centuries of cancer research worldwide it is still unclear if the somatic mutation that causes cancer is the one that alters the number of chromosomes (causes aneuploidy), or one that alters specific genes. Most cancer phenotypes are unstable and this phenomenon became known as the "genetic instability" of cancer cells. Duesberg and others [127], based on its mutagenic potential, have recently reconsidered aneuploidy as a cause of cancer. These researchers hypothesized that aneuploidy alters the dosage of thousands of structural and regulatory gene products as a result of multiplication or division of complete biochemical pathways, and, by doing so, offers a plausible explanation for the many dominant phenotypes of cancer genes. This hypothesis would exactly explain the cancer-specific DNA indices, expression profiles of thousands of genes, neoantigens, autonomous growth, nuclear morphology alterations usually not observed in conventional gene mutations. The mechanism of carcinogenesis via aneuploidy is divided into two stages; the first stage requires generation of aneuploidy by exposure to genotoxic physical carcinogens (X-rays, radiation) fragmenting chromosomes or by mutation of genes regulating mitosis. There is much evidence that cancers being caused by genotoxic physical and chemical carcinogens are always aneuploid. The second stage requires generation of neoplastic karyotypes via autocatalytic karyotype variation and evolution resulting from imposed imbalance on the genes of the spindle apparatus, causing abnormal ratios of spindle proteins, centrosomal proteins and even abnormal numbers of centromers. According to Duesberg's theory, the process of aneuploidy-catalyzed chromosome re-assortment would generate lethal, pre-neoplastic and neoplastic karyotypes and would require a very long time from exposure to the carcinogen to commencement of carcinogenesis. By contrast, the mutation hypothesis predicts instant neoplastic transformation as observed exclusively in the case of oncogenic retroviruses.

The aneuploidy theory of cancer, although controversial at present, could have a practical value for cancer patients. According to David Rasnick, aneuploid tumour stability could be easily disrupted by environmental changes such as major changes in diet [128]. The slow acceptance of this theory has already stimulated research into compounds that cause or prevent aneuploidy.

Numerous epidemiological studies have demonstrated a lower risk of cancer among individuals whose diet includes a relatively large amount of vegetables, fruits and plant products, all containing different vitamins and micronutrients with ability to prevent carcinogenesis by interfering with detrimental actions of mutagens, carcinogens and tumour promoters. Recent studies demonstrate that plants rich in compounds such as avicins (triterpenoid saponins) are able to inhibit oxidative stress and promote apoptosis of pre-malignant and malignant cells of skin cancer in the murine model, suggesting the potential to prevent other epithelial tumours also in humans [129].
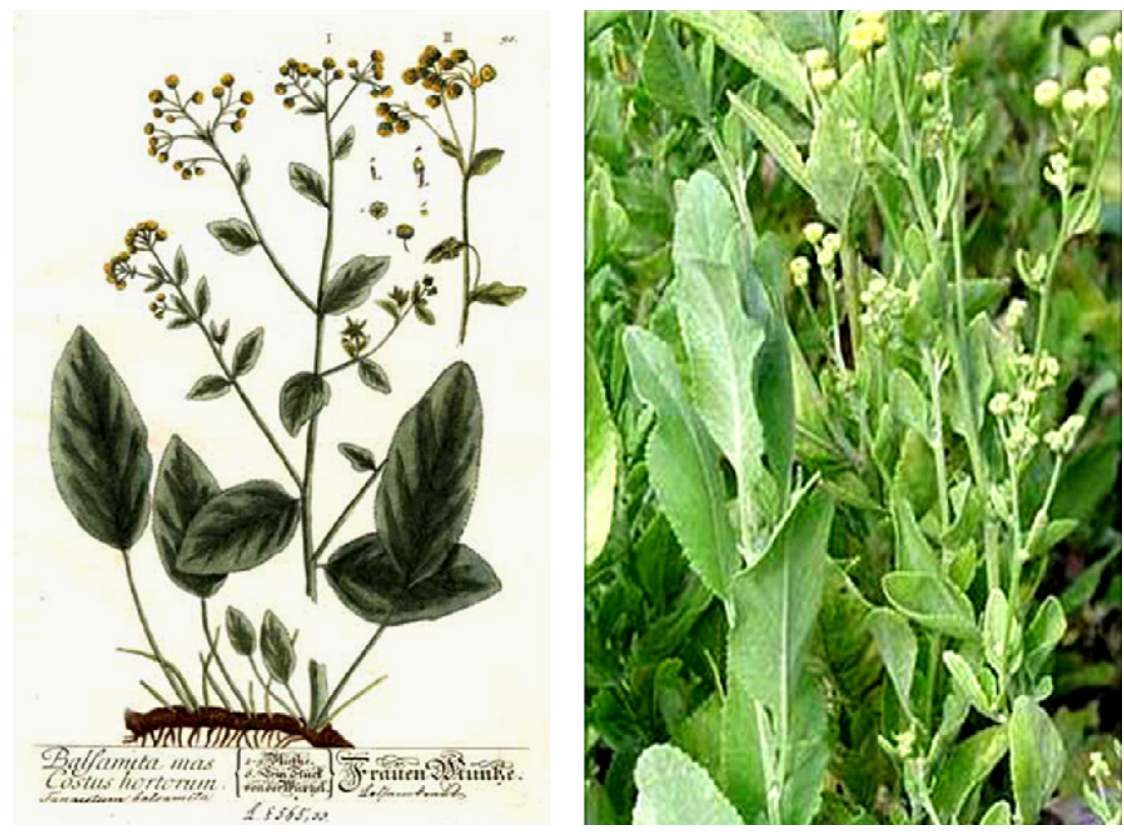

Fig. 2. Images of Balsamite major Desf. were obtained from the archives of Officina Profumo-Farmaceutica "Santa Maria Novella" Florence, Italy. 


\section{Balsamita major: a new natural candidate anticancer compound}

Recently, the preliminary assessment of the anti-inflammatory antioxidative and possible anti-tumour properties of Balsamita major Desf. commonly known as a costmary (Fig. 2), has been completed at the Consiglio Nazionale delle Ricerche (CNR) Istituto per lo Studio degli Ecosistemi of Florence in collaboration with the Universities of Siena and Pisa (Italy) and the Officina Profumo Farmaceutica Santa Maria Novella, a historical "institution" of herbal medicine and cosmetics established in 1612 and continually operating in Florence, Italy. The preliminary data demonstrate a rich source of potential natural antioxidants and anti-inflammatory compounds present at relatively high concentration in aqueous extracts of the dry plant, without any cytotoxic effects detected so far. The anti-inflammatory effect was demonstrated to be mediated via inhibition of IL- 6 expression by human peripheral blood mononuclear cells (monocytes stimulated by bacterial lipopolysaccharide) and confirms the historical importance of Balsamite major Desf in herbal medicine.

\section{Conjugation of psolaren with antisense oligonucleotides: a chimera of old and new}

The antisense strategy is widely used to modulate gene expression at a post-transcriptional level both as a research tool and as potential cancer gene therapy [130].

A vexata quaestio is how antisense oligonucleotides are actually cancer gene specific, which requires that its target be restricted to cancer cells and be absent in their normal counterpart. Chromosomal translocations or inversions are the only targets responding to this requirement. Indeed, cancer specificity of a variety of antisense oligonucleotides targeting either hybrid transcripts or hybrid genes has been proven [131,132]. However, because of the high genetic variability of cancer cells, any one-gene targeting antisense oligonucleotide cannot succeed in killing cancer. Thus, potential antisense therapeutics are now exploited in combination with conventional anticancer drugs (including natural compounds) targeting signalling pathways of proliferation and apoptosis [133].

Psoralen is a natural photodynamic compound belonging to the family of furocoumarins, whose chemical structure consists of a furan ring fused with coumarin. It is produced by a variety of plants as a natural defence against pest. It occurs in Psoralea corylifolia, from which the natural compound derives its name, as well as in the common fig, celery, parsley, and parsnips. Given its extended $\pi$-electron system, psoralen displays UV light-induced photosensitizing activity, useful in photodynamic treatment of various diseases, including psoriasis, vitiligo and other skin conditions like cutaneous T-cell lymphoma [134,135]. Psoralene forms interstrand cross-links as well as thymine monoadducts with DNA upon UV light activation. Photodynamic treatments consist of the topical or oral application of psoralen followed by exposure to photoactivating UV light in the range of $315-400 \mathrm{~nm}$ of wavelength (PUVA).

Conjugation of established anticancer drugs to cancer specific antisense oligonucleotides to give rise to new highly synergistic chimeric therapeutics has been proposed. As a paradigm, conjugates of psoralen or its derivatives with antisense oligonucleotides targeting cancer specific fused genes derived from genomic translocations have been synthesized. The potent, generalized, cytotoxic effects of psoralen are timely and spatially restricted by cooperation of the antisense moiety of the chimera, which specifically targets the fusion gene. Thus, they are exerted based on the ability of psolaren to be activated by UV light, only on the condition that antisense complements its target.

Psoralen-conjugated antisense oligonucleotides have been successfully used to silence specific genes involved in cancerogenesis, such as mutated K-Ras mRNA [136], human papillomavirus E6 oncogene protein mRNA [137] and c-myc mRNA [138].

\section{Conclusions}

The medical treatment of cancer has made substantial improvements since the early years of modern anti-tumour drug research. A selected number of human malignancies (e.g. childhood lymphoblastic leukaemia, lymphomas and testicular cancer) can be cured with the today's therapies and prolonged survival has been obtained in several others [139]. The identification and development of natural compounds and their derivatives have greatly contributed to this progress and many of these compounds are now being used in clinical practice.

Nature is still today a rich source of active principles against cancer cells. Natural compounds comprise either classical cytotoxic moieties targeting nonspecific macromolecules expressed by cancer cells and to a lesser extent by normal proliferating cells (e.g. DNA, enzymes, microtubules) or new compounds targeting macromolecules specifically expressed on cancer cells (e.g. oncogenic signal transduction pathways). Another relevant field of application of natural compounds is cancer chemoprevention since these compounds may inhibit specific processes involved in cancerogenesis. Even the popular press frequently publishes articles about cancer chemoprevention and its potential benefits and always reports about newly discovered exotic natural compounds with possibly relevant preventive properties. However, despite a robust molecular rationale for this strategy, preclinical and clinical data in this field are still scanty and no controlled clinical trial has yet been published demonstrating relevant clinical advantages.

It is important to emphasize that only rigorous preclinical and clinical studies along with a precise understanding of the pharmacology of new compounds may assure the selection of active and safe anticancer and chemopreventive drugs, including natural compounds.

A controversial issue relates to the spontaneous use by cancer patients of complementary therapies comprising nutraceuticals and functional food. Few diseases evoke as much emotion, psychological and physical pain as cancer. This justifies the desperate search by cancer patients for therapies that hold the promise of a concrete breakthrough and cure beyond the remedies that physicians can offer them. The attention of the media on these topics is high and stimulates the expectations of patients, relatives and the entire society, sometimes even unduly, by inducing glimmers of hope which may be unrealistic. Extreme caution must be exerted in allowing patients to assume complementary therapies since today no data on their therapeutic benefits are available and they may induce relevant side effects and drug interactions. The use of complementary therapies in addition to the standard chemotherapy may also produce detrimental effects as recently suggested for vitamin C in in vitro models [140], despite other promising preliminary preclinical and clinical data [141].

In conclusion, the application of natural compounds in the treatment of cancer, the very common "plague" of our modern times, has resulted in increased therapeutic efficacy. Research results both testify to the evolution of knowledge coming from pharmacognosy and its historical roots in ancient herbal medicine, as well as to the great possibilities of future progress by means of a rational, natural product-based drug discovery approach.

\section{Acknowledgements}

This review is partially supported by contributions of MIUR (PRIN 2007 to S.C.), AIRC ( to S.C.), Ente Cassa di Risparmio di Firenze 
(to S.C. and E.M.), Fondazione Cassa di Risparmio di Lucca (to S.C.) and Associazione Giacomo Onlus (to E.M.).

\section{References}

[1] Graham JG, Quinn ML, Fabricant DS, Farnsworth NR. Plants used against cancer-an extension of the work of Jonathan Hartwell. J Ethnopharmacol 2000:347-77.

[2] Abdullaev FI. Cancer chemopreventive and tumoricidal properties of saffron (Crocus sativus L.). Exp Biol Med 2005;227:20-5.

[3] Schmidt M, Betti G, Hensel A. Saffron in phytotherapy: pharmacology and clinical use. Wien Med Wochenschr 2007;157:315-409, doi:10.1007/s10354-007-0428-4

[4] Tasdemir D, Mallon R, Greenstain M, Feldberg LR, Kim SC, Collins K, et al. Aldisine Alcaloids from the Philipine sponge Stylissa massa are potent inhibitors of mitogen-activated protein kinase-1 (MEK-1). J Med Chem 2002;45:529-32.

[5] Marshall KM, Matsumoto LL, Holden JA, Concepcion GP, Tasdemir D, Ireland $\mathrm{CM}$, et al. The antineoplastic and novel Topoisomerase II mediated cytotoxicity of neoamphimedine, a marine pyridoacridine. Biochem Pharmacol 2003;66:447-58.

[6] Lansky EP, Newman RA. Punica granatum (pomegranate) and its potential for prevention and treatment of inflammation and cancer. J Ethnopharmacol 2007;19:177-206.

[7] Ariga T, Seki T. Antithrombotic and anticancer effects of garlic-derived sulfur compounds: a review. Biofactors 2006;26:93-103.

[8] Kinghorn AD, Farnsworth NR, Soejarto DD, Cordell GA, Swanson SM, Pezzuto JM, et al. Novel strategies for the discovery of plant-derived anticancer agents. Pharmaceut Biol 2003;41:53-67.

[9] Song JI, Dumais MR. From yew to us: the curious development of taxol. JAMA 1991;266:1281.

[10] Holton RA, Somoza C, Kim HB, Liang F, Biediger RJ, Boatman PD, et al. First Total Synthesis of Taxol. J Am Chem Soc 1994;116:1597-9.

[11] Adams JD, Flora KP, Goldspiel BR, Wilson JW, Arbuck SG, Finley R. Taxol: a history of pharmaceutical development and current pharmaceutical concerns. J Natl Cancer Inst Monogr 1993;15:141-7.

[12] Waksman SA, Woodruff HB. Actinomyces antibioticus, a new soil organism antagonistic to pathogenic and non-pathogenic bacteria. J Bacteriol 1941;42:231-49.

[13] Farber S, Pinkel D, Sears EM, Toch R. Advances in chemotherapy of cancer in man. Adv Cancer Res 1956;4:1-71.

[14] Keidan SE. The chemotherapy of cancer in children. Proc R Soc Med 1966;59:211-2.

[15] Di Marco A, Gaetani M, Orezzi P, Scarpinato B, Silvestrini R, Soldati M, et al. Daunomycin, a new antibiotic of the rhodomycin group. Nature 1964;201:706-7.

[16] Arcamone F, Franceschi G, Penco S, Selva A. Adriamycin (14hydroxydaunomycin) (Italy), a novel antitumor antibiotic. Tetrahedron Lett 1969;13:1007-10.

[17] Bergmann W, Feeney RJ. The isolation of a new thymine pentoside from sponges. J Am Chem Soc 1950;72:2809-10.

[18] Bergmann W, Feeney RJ. Nucleosides of sponges: discovery of the arabinosebased nucleotides-Tethya crypta. J Org Chem 1951;16:981-7.

[19] Simmons TL, Andrianasolo E, McPhail K, Flatt P, Gerwick WH. Marine natural products as anticancer drugs. Mol Cancer Ther 2005;4:333-42.

[20] Singh R, Sharma M, Joshi P, Rawat DS. Clinical status of anti-cancer agents derived from marine sources. Anticancer Agents Med Chem 2008;8:603-17.

[21] Luduena RF. Multiple forms of tubulin: different gene products and covalent modifications. Int Rev Cytol 1998;178:207-75.

[22] Jordan MA, Wilson L. Microtubules as a target for anticancer drugs. Nat Rev 2004;4:253-65, doi:10.1038/nrc1317.

[23] Itoh TJ, Hotani H. Microtubule-stabilizing activity of microtubuleassociated proteins (MAPs) is due to increase in frequency of rescue in dynamic instability: shortening length decreases with binding of MAPs onto microtubules. Cell Struct Funct 1994;19:279-90.

[24] Fahy J. Modifications in the "upper" velbenamine part of the Vinca alkaloids have major implications for tubulin interacting activities. Curr Pharm Des 2001;7:1181-97.

[25] Yun-San Yip A, Yuen-Yuen Ong E, Chow LW. Vinflunine: clinical perspectives of an emerging anticancer agent. Expert Opin Investig Drugs 2008;17:583-91, doi:10.1517/13543784.17.4.583.

[26] Ngan VK, Bellman K, Hill BT, Wilson L, Jordan MA. Mechanism of mitotic block and inhibition of cell proliferation by the semisynthetic Vinca alkaloids vinorelbine and its newer derivative vinflunine. Mol Pharmacol 2001;60:225-32.

[27] Nobili S, Landini I, Giglioni B, Mini E. Pharmacological strategies for overcoming multidrug resistance. Curr Drug Targets 2006;7:861-79.

[28] Lautier D, Canitrot Y, Deeley RG, Cole SP. Multidrug resistance mediated by the multidrug resistance protein (MRP) gene. Biochem Pharmacol 1996;52:967-77.

[29] Zhang J, Alter N, Reed JC, Borner C, Obeid LM, Hannun YA. Bcl-2 interrupts the ceramide-mediated pathway of cell death. Proc Natl Acad Sci USA 1996;93:5325-8.

[30] Simonian PL, Grillot DA, Nunez G. Bcl-2 and Bcl-XL can differentially block chemotherapy-induced cell death. Blood 1997;90:1208-16.
[31] Leveque D, Jehl F. Molecular pharmacokinetics of catharanthus (vinca) alkaloids. J Clin Pharmacol 2007;47:579-88, doi:10.1177/0091270007299430.

[32] Aapro MS, Conte P. Esteban González E. Trillet-Lenoir V Drugs 2007;67:657-67.

[33] Eggen M, Georg GI. The cryptophycins: their synthesis and anticancer activity. Med Res Rev 2002;22:85-101.

[34] D'Agostino G, del Campo J, Mellado B, Izquierdo MA, Minarik T, Cirri L, et al. A multicenter phase II study of the cryptophycin analog LY355703 in patients with platinum-resistant ovarian cancer. Int J Gynecol Cancer 2006;16:71-6, doi:10.1111/j.1525-1438.2006.00276.x.

[35] Kindler HL, Tothy PK, Wolff R, McCormack RA, Abbruzzese JL, Mani S, et al. Phase II trials of dolastatin-10 in advanced pancreaticobiliary cancers. Invest New Drugs 2005;23:489-93, doi:10.1007/s10637-005-2909-X.

[36] Perez EA, Hillman DW, Fishkin PA, KrookJE, Tan WW, Kuriakose PA, et al. Phase II trial of dolastatin-10 in patients with advanced breast cancer. Invest New Drugs 2005;23:257-61, doi:10.1007/s10637-005-6735-y.

[37] Hoffman MA, Blessing JA, Lentz SS, Gynecologic Oncology Group Study. A phase II trial of dolastatin-10 in recurrent platinum-sensitive ovarian carcinoma: a Gynecologic Oncology Group study. Gynecol Oncol 2003;89:95-8.

[38] Tamura K, Nakagawa K, Kurata T, Satoh T, Nogami T, Takeda K, et al. Phase I study of TZT-1027, a novel synthetic dolastatin 10 derivative and inhibitor of tubulin polymerization, which was administered to patients with advanced solid tumors on days 1 and 8 in 3-week courses. Cancer Chemother Pharmacol 2007;60:285-93, doi:10.1007/s00280-006-0382-7.

[39] Bai RL, Paull KD, Herald CL, Malspeis L, Pettit GR, Hamel E. Halichondrin B and homohalichondrin $\mathrm{B}$, marine natural products binding in the vinca domain of tubulin. Discovery of tubulin-based mechanism of action by analysis of differential cytotoxicity data. J Biol Chem 1991;266:15882-9.

[40] http://www.clinicaltrials.gov.

[41] Wani MC, Taylor HL, Wall ME, Coggon P, McPhail AT. Plant antitumor agents. VI. The isolation and structure of taxol, a novel antileukemic and antitumor agent from Taxus brevifolia. J Am Chem Soc 1971;93:2325-7.

[42] ten Tije AJ, Verweij J, Loos WJ, Sparreboom A. Pharmacological effects of formulation vehicles: implications for cancer chemotherapy. Clin Pharmacokinet 2003;42:665-85

[43] Hennenfent KL, Govindan R. Novel formulations of taxanes: a review. Old wine in a new bottle? Ann Oncol 2006;17:735-49, doi:10.1093/annonc/mdj100.

[44] Rowinsky EK, Calvo E. Novel agents that target tubulin and related elements. Semin Oncol 2006;33:421-35, doi:10.1053/j.seminoncol.2006.04.006.

[45] Kingston DGI. History and chemistry. In: McGuire WP, Rowinsky EK, editors Paclitaxel in cancer treatment. New York: Marcel Dekker; 1995. p. 1-33.

[46] Ringel I, Horwitz SB. Studies with RP 56976 (Taxotere): a semisynthetic analogue of Taxol. J Natl Cancer Inst 1991;83:288-91.

[47] Weiss RB, Donehower RC, Wiernik PH, Ohnuma T, Gralla RJ, Trump DL, et al. Hypersensitivity reactions from taxol. J Clin Oncol 1990;8:1263-8.

[48] Onetto N, Canetta R, Winograd B, Catane R, Dougan M, Grechko J, et al. Overview of taxol safety. J Natl Cancer Inst 1993;15:131-9.

[49] Winer E, Berry DA, Woolf S, Duggan D, Kornblith A, Harris LN, et al. Failure of higher-dose paclitaxel to improve outcome in patients with metastatic breast cancer: cancer and leukemia group B trial 9342. J Clin Oncol 2004;22:2061-8, doi:10.1200/JCO.2004.08.048.

[50] Gueritte-Voegelein F, Guenard D, Lavelle F, Le Goff MT, Mangatal L, Potier PJ. Med Chem 1991;34:992-8.

[51] Horwitz SB, Cohen D, Rao S, Ringel I, Shen H-J, Yang C-PH. J Natl Cancer Inst Monogr 1993;15:55-61, 10.1146/annurev.med.48.1.353.

[52] Rowinsky EK. The development and clinical utility of the taxane class of antimicrotubule chemo-therapy agents. Annu Rev Med 1997;48:353-74.

[53] Orr GA, Verdier-Pinard P, McDaid H, Horwitz SB. Mechanisms of Taxol resistance related to microtubules. Oncogene 2003;22:7280-95, doi:10.1038/sj.onc.1206934.

[54] Dorr RT. Pharmacology of the taxanes. Pharmacotherapy 1997; 17:96S-104S

[55] Hennequin C, Giocanti N, Favaudon V. S-phase specificity of cell killing by docetaxel (Taxotere) in synchronized HeLa cells. Br J Cancer 1995;71: 1194-8.

[56] Haldar S, Basu A, Croce CM. Bc12 is the guardian of microtubule integrity. Cancer Res 1997;57:229-33.

[57] Ding AH, Porteu F, Sanchez E, Nathan CF. Shared actions of endotoxin and Taxol on TNF receptors and TNF release. Science 1990;248:370-2.

[58] McGrogan BT, Gilmartin B, Carney DN, McCann A. Taxanes, microtubules and chemoresistant breast cancer. Biochim Biophys Acta 2008;1785:96-132 doi:10.1016/j.bbcan.2007.10.004.

[59] Lavelle F, Bissery MC, Combeau C, Riou JF, Vrignaud P, Andre S. Preclinical evaluation of docetaxel (Taxotere). Semin Oncol 1995;22:3-16.

[60] Valero V, Jones SE, Von Hoff DD, Booser DJ, Mennel RG, Ravdin PM, et al. A phase II study of docetaxel in patients with paclitaxel-resistant metastatic breast cancer. J Clin Oncol 1998;16:3362-8.

[61] Mekhail TM, Markman M. Paclitaxel in cancer therapy. Expert Opin Pharmacother 2002;3:755-66, doi:10.1517/14656566.3.6.755.

[62] Ramaswamy B, Puhalla S. Docetaxel: a tubulin-stabilizing agent approved for the management of several solid tumors. Drugs Today (Barc) 2006;42:265-79, doi:10.1358/dot.2006.42.4.9686.

[63] Conlin A, Fornier M, Hudis C, Kar S, Kirkpatrick P. Ixabepilone. Nat Rev Drug Discov 2007;6:953-4.

[64] Nobili S, Mini E. Alternative approaches to overcome multidrug resistance. In: Colabufo N, editor. Multi-drug resistance: biological pharmaceutical advance 
in the antitumour treatment. India: Research Signpost, Kerala; 2008. p. 101-39.

[65] Florence GJ, Gardner NM, Paterson I. Development of practical syntheses of the marine anticancer agents discodermolide and dictyostatin. Nat Prod Rep 2008;25:342-75, doi:10.1039/b705661n.

[66] Hartmann JT, Lipp H-P. Camptothecin and podophyllotoxin derivatives. Drug Saf 2006;29:209-300.

[67] Cortes-Funes H, Coronado C. Role of anthracyclines in the era of targeted therapy. Cardiovasc Toxicol 2007;7:56-60, doi:10.1007/s12012-007-0015-3.

[68] Wall ME, Wani MC, Cook CE, Palmer KH, McPhail AT, Sim GA. Plant antitumor agents. I. The isolation and structure of camptothecin, a novel alkaloidal leukemia and tumor inhibitor from Camptotheca acuminate. J Am Chem Soc 1966;88:3888-90.

[69] Malonne H, Atassi G. DNA topoisomerase targeting drugs: mechanisms of action and perspectives. Anticancer Drugs 1997;8:811-22.

[70] Teicher BA. Next generation topoisomerase I inhibitors: rationale and biomarker strategies. Biochem Pharmacol 2008;75:1262-71, doi:10.1016/j.bcp.2007.10.016.

[71] Garcia-Carbonero R, Supko JG. Current perspectives on the clinical experience, pharmacology, and continued development of the camptothecins. Clin Cancer Res 2002;8:641-61.

[72] Kingsbury WD, Boehm JC, Jakas DR, Holden KG, Hecht SM, Gallagher G, et al. Synthesis of water-soluble (aminoalkyl)camptothecin analogues: inhibition of topoisomerase I and antitumor activity. J Med Chem 1991;34:98-107.

[73] Pommier Y, Topoisomerase. I inhibitors: camptothecins and beyond. Nat Rev 2006;6:789-802, doi:10.1038/nrc1977.

[74] Hsiang YH, Hertzberg R, Hecht S, Liu LF. Camptothecin induces proteinlinked DNA breaks via mammalian DNA topoisomerase I. J Biol Chem 1985;260:14873-8.

[75] Xu Y, Villanova-Calero MA. Irinotecan: mechanisms of tumor resistance and novel strategies for modulating its activity. Ann Oncol 2002;13:1841-51.

[76] Herzog TJ. Update on the role of topotecan in the treatment of recurrent ovarian cancer. Oncologist 2002;7(Suppl 5):3-10.

[77] Creemers GJ, Bolis G, Gore M, Scarfone G, Lacave AJ, Guastalla JP, et al. Topotecan, an active drug in the second-line treatment of epithelial ovarian cancer: results of a large European phase II study. J Clin Oncol 1996;14:3056-61.

[78] Douillard JY, Cunningham D, Roth AD, Navarro M, James RD, Karasek P, et al. Irinotecan combined with fluorouracil compared with fluorouracil alone as first-line treatment for metastatic colorectal cancer: a multicentre randomised trial. Lancet 2000;355:1041-7.

[79] Board RE, Valle JW. Metastatic colorectal cancer: current systemic treatment options. Drugs 2007;67:1851-67.

[80] Hyatt JL, Tsurkan L, Morton CL, Yoon KJ, Harel M, Brumshtein B, et al. Inhibition of acetylcholinesterase by the anticancer prodrug CPT-11. Chem Biol Interact 2005;157-158:247-52, doi:10.1016/j.cbi.2005.10.033.

[81] McLeod H. Epipodophyllotoxins. In: Schellens JHM, McLeod HL, Newell DR, editors. Cancer clinical pharmacology. Oxford University Press; 2005. p. 104-16.

[82] Watt PM, Hickson ID. Structure and function of type II DNA topoisomerases. Biochem J 1994;303:681-95.

[83] Lowe SW, Ruley HE, Jacks T, Housman DE. p53-dependent apoptosis modulates the cytotoxicity of anticancer agents. Cell 1993;74:957-67.

[84] Hudson MM, Weinstein HJ, Donaldson SS, Greenwald C, Kun L, Tarbell NJ, et al. J Clin Oncol 1993;11:1080-4.

[85] Ogle KM, Kennedy BJ. Hypersensitivity reactions to etoposide. A case report and review of the literature. Am J Clin Oncol 1988;11:663-5.

[86] Robert J. Anthracyclines. Chapter 9. In: Schellens JHM, McLeod HL, Newell DR, editors. Cancer clinical pharmacol. Oxford University Press; 2005. p. 117-33.

[87] Zunino F, Capranico G. DNA topisomerasas II as the primary target of antitumoral anthracyclines. Anticancer Drug Des 1990;5:307-17.

[88] Tewey KM, Chen GL, Nelson EM, Liu LF. Intercalative antitumor drugs interfere with the breakage-reunion reaction of mammalian DNA topoisomerase II. J Biol Chem 1984;259:9182-7.

[89] Doroshow J. Anthracyclines and anthracenediones. Cancer Chemother Biother 2001;13:500-37.

[90] Sinha BK. Free radicals in anticancer drug pharmacology. Chem Biol Interact 1989;69:293-317.

[91] Cole SP, Bhardwaj G, Gerlach JH, Mackie JE, Grant CE, Almquist KC, et al. Overexpression of a transporter gene in a multidrug-resistant human lung cancer cell line. Science 1992;258:1650-4.

[92] Friche E, Skovsgaardt T, Nissen JI. Anthracycline resistance. Acta Oncol 1989;28:877-81.

[93] Wang HK. Flavopiridol National Cancer Institute. Curr Opin Investig Drugs 2001;2:1149-55.

[94] Blagosklonny MV. Flavopiridol, an inhibitor of transcription: implications, problems and solutions. Cell Cycle 2004;3:1537-42.

[95] Senderowicz AM, Headlee D, Stinson SF, Lush RM, Kalil N, Villalba L, et al. Phase I trial of continuous infusion flavopiridol, a novel cyclindependent kinase inhibitor, in patients with refractory neoplasms. J Clin Oncol 1998:16:2986-99.

[96] Wright J, Blatner GL, Cheson BD. Clinical trials referral resource. Clinical trials of flavopiridol. Oncology 1998;12:1023-4, 1018.

[97] Powell RG, Weisleder D, Smith CR, Rohwedder WK. Structures of harringtonine, isoharringtonine, and homoharringtonine. Tetrahydron Lett 1970;11:815-8.
[98] Kantarjian HM, O’Brien S, Anderlini P, Talpaz M. Treatment of myelogenous leukemia: current status and investigational options. Blood 1996;87:3069-81.

[99] Zhou DC, Zittoun R, Marie JP. Homoharringtonine: an effective new natural product in cancer chemotherapy. Bull Cancer 1995;82:987-95.

[100] Li YZ, Li CJ, Pinto AV, Pardee AB. Release of mitochondrial cytochrome c in both apoptosis and necrosis induced by $\beta$-lapachone in human carcinoma cells. Mol Med 1999;5:232-9.

[101] Banerjee S, Wang Z, Mohammad M, Sarkar FH, Mohammad RM. Efficacy of selected natural products as therapeutic agents against cancer. J Natl Prod 2008;71:492-6, doi:10.1021/np0705716.

[102] Hartford CM, Ratain MJ. Rapamycin: something old, something new, sometimes borrowed and now renewed. Clin Pharmacol Ther 2007;82:381-8, doi:10.1038/sj.clpt.6100317.

[103] Schulte TW, Neckers LM. The benzoquinone ansamycin 17-allylamino17demethoxygeldanamycin binds to HSP90 and shares important biologic activities with geldanamycin. Cancer Chemother Pharmacol 1998;42:273-9.

[104] Ohji G, Hidayat S, Nakashima A, Tokunaga C, Oshiro N, Yoshino K, et al. Suppression of the mTOR-raptor signaling pathway by the inhibitor of heat shock protein 90 geldanamycin. J Biochem 2006;139:129-35, doi: $10.1093 / \mathrm{jb} / \mathrm{mvj008.}$

[105] Kidd JG. Regression of transplanted lymphomas induced in vivo by means of normal guinea pig serum. I. Course of transplanted cancers of various kinds in mice and rats given guinea pig serum, horse serum, or rabbit serum. J Exp Med 1953;98:565-82.

[106] Kidd JG. Regression of transplanted lymphomas induced in vivo by means of normal guinea pig serum. II. Studies on the nature of the active serum constituent: histological mechanism of the regression: tests for effects of guinea pig serum on lymphoma cells in vitro: discussion. Exp Med 1953;98:583-606.

[107] Narta UK, Kanwar SS, Azmi W. Pharmacological and clinical evaluation of L-asparaginase in the treatment of leukaemia. Crit Rev Oncol Hematol 2007;61:208-21, doi:10.1016/j.critrevonc.2006.07.009.

[108] Le Cesne A, Blay JY, Judson I, Van Oosterom A, Verweij J, Radford J, et al. Phase II study of ET-743 in advanced soft tissue sarcomas: a European Organisation for the Research and Treatment of Cancer (EORTC) soft tissue and bone sarcoma group trial. J Clin Oncol 2005;23:576-84.

[109] Monk BJ, Herzog T, Kaye S, Krasner CN, Vermorken J, Muggia F, et al. A randomized phase III study of trabectedin with pegylated liposomal doxorubicin (PLD) versus PLD in relapsed, recurrent ovarian cancer (OC). Ann Oncol 2008;19(Suppl 8):LBA4.

[110] Carter N, Keam SJ. Trabectedin-a review of its use in the management of soft tissue sarcoma and ovarian cancer. Drugs 2007;67:2257-76.

[111] Kortmansky J, Schwartz GK. Bryostatin-1: a novel PKC inhibitor in clinical development. Cancer Invest 2003;21:924-36.

[112] Dumez H, Gall H, Capdeville R, Dutreix C, van Oosterom AT, Giaccone G. A phase I and pharmacokinetic study of LAF389 administered to patients with advanced cancer. Anticancer Drugs 2007;18:219-25, doi:10.1097/CAD.0b013e328010ef5b.

[113] Duvoix A, Blasius R, Delhalle S, Schnekenburger M, Morceau F, Henry E, et al. Chemopreventive and therapeutic effects of curcumin. Cancer Lett 2005;223:181-90, doi:10.1016/j.canlet.2004.09.041.

[114] Johnson JJ, Mukhtar H. Curcumin for chemoprevention of colon cancer. Cancer Lett 2007;255:170-81, doi:10.1016/j.canlet.2007.03.005.

[115] Athar M, Back JH, Tang X, Kim KH, Kopelovich L, Bickers DR, et al. Resveratrol: a review of preclinical studies for human cancer prevention. Toxicol Appl Pharmacol 2007;224:274-83, doi:10.1016/j.taap.2006.12.025.

[116] Foster CB, Amason JT, Briggs CJ. Natural health products and drug disposition. Annu Rev Pharmacol Toxicol 2005;45:203-26, doi:10.1146/annurev.pharmtox.45.120403.095950.

[117] Bingham SA, Day NE, Luben R, Ferrari P, Slimani N, Norat T, et al. European prospective investigation into cancer and nutrition. Dietary fibre in food and protection against colorectal cancer in the European Prospective Investigation into Cancer and Nutrition (EPIC): an observational study. Lancet 2003;361:1496-501.

[118] Eskin NA, Raju J, Bird RP. Novel mucilage fraction of Sinapis alba L. (mustard) reduces azoxymethane-induced colonic aberrant crypt foci formation in F344 and Zucker obese rats. Phytomedicine 2007;14:479-85, doi:10.1016/j.phymed.2006.09.016.

[119] Surh YJ. Cancer chemoprevention with dietary phytochemicals. Nat Rev Cancer 2003;3:768-80, doi:10.1038/nrc1189.

[120] Lau A, Villeneuve NF, Sun Z, Wong PK, Zhang DD. Dual roles of NrF2 in cancer. Pharmacol Res 2008;58:262-70, doi:10.1016/j.phrs.2008.09.003.

[121] Jeong WS, Jun M, Kong AN. Nrf2: a potential molecular target for cancer chemoprevention by natural compounds. Antioxid Redox Signal 2006;8:99-106.

[122] Wang XJ, Sun Z, Villeneuve NF, Zhang S, Zhao F, Li Y, et al. Nrf2 enhances resistance of cancer cells to chemotherapeutic drugs, the dark side of Nrf2. Carcinogenesis 2008;29:1235-43, doi:10.1093/carcin/bgn095.

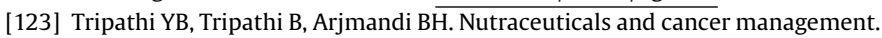
Front Biosci 2005;10:1607-18.

[124] Balachandran P, Govindarajan R. Cancer-an ayurvedic perspective. Pharmacol Res 2005;51:19-30, doi:10.1016/j.phrs.2004.04.010.

[125] Arnold JT, Wilkinson BP, Korytynski EA, Steel VE. Chemopreventive activity of Maharishi Amrit Kalash and related agents in rat tracheal epithelial and human tumor cells. Proc Am Assoc Cancer Res 1991;32:128-31. 
[126] Sharma HM, Dwivedi C, Satter BC, Gudehithlu KP, Abou-Issa H, Malarkey W, et al. Antineoplastic properties of Maharishi-4 against DMBA-induced mammary tumors in rats. Pharmacol Biochem Behav 1990;35:767-73.

[127] Duesberg P, Stindl R, Li RH, Hehlmann R, Rasnick D. Aneuploidy versus gene mutation as a cause of cancer. Curr Sci 2001;81:490-500.

[128] Duesberg P, Li R, Rasnick D. Aneuploidy approaching a perfect score in predicting and preventing cancer: highlights from a conference held in Oakland, CA in January 2004. Cell Cycle 2004;3:823-8

[129] Hanausek M, Ganesh P, Walaszek Z, Arntzen CJ, Slaga TJ, Gutterman U. Avicins, a family of triterpenoid saponins from Acacia victoriae (Bentham), suppress $\mathrm{H}$-ras mutations and aneuploidy in murine skin carcinogenesis model. Proc Natl Acad Sci USA 2001;98:11551-6, doi:10.1073/pnas.191363198.

[130] Schiavone N, Donnini M, Nicolin A, Capaccioli S. Antisense oligonucleotide drug design. Curr Pharm Des 2004;10:769-84.

[131] Rapozzi V, Cogoi S, Xodo LE. Antisense locked nucleic acids efficiently suppress $\mathrm{BCR} / \mathrm{ABL}$ and induce cell growth decline and apoptosis in leukemic cells. Mol Cancer Ther 2006;5:1683-92.

[132] Wu AG, Joshi SS, Chan WC, Iversen PL, Jackson JD, Kessinger A, et al. Effects of BCR-ABL antisense oligonucleotides (AS-ODN) on human chronic myeloid leukemic cells: AS-ODN as effective purging agents. Leuk Lymphoma 1995;20:67-76.

[133] Biroccio A, Leonetti C, Zupi G. The future of antisense therapy: combination with anticancer treatments. Oncogene 2003;22:6579-88.
[134] Honig B, Morison WL, Karp D. Photochemotherapy beyond psoriasis. J Am Acad Dermatol 1994;31:775-90.

[135] Dalla Via L, Marciani Magno S. Photochemotherapy in the treatment of cancer. Curr Med Chem 2001;8:1405-18.

[136] Higuchi M, Yamayoshi A, Kobori A, Murakami A. Selective regulation of mutant K-ras mRNA expression by photo-cross-linking antisense oligonucleotide. Nucleic Acids Symp Ser (Oxf) 2007;51:443-4

[137] Yamayoshi A, Kato K, Iwase R, Yamaoka T, Wake N, Murakami A. Photodynamic antisense therapy: regulation of cervical carcinoma cells by psoralen-conjugated oligonucleotides. Nucleic Acids Res Suppl 2003;3: 75-6.

[138] Stewart DA, Thomas SD, Mayfield CA, Miller DM. Psoralen-modified clampforming antisense oligonucleotides reduce cellular c-Myc protein expression and B16-F0 proliferation. Nucleic Acids Res 2001;29:4052-61.

[139] Garattini S, La Vecchia C. Perspectives in cancer chemotherapy. Eur J Cancer 2001;37(Suppl 8):S128-47, doi:10.1158/0008-5472.CAN-08-1490.

[140] Heaney ML, Gardner JR, Karasavvas N, Golde DW, Scheinberg DA, Smith EA, et al. Vitamin $C$ antagonizes the cytotoxic effects of antineoplastic drugs. Cancer Res 2008;68:8031-8.

[141] Frei B, Lawson S. Vitamin C and cancer revisited. Proc Natl Acad Sci USA 2008;105:11037-8, doi:10.1073/pnas.0806433105. 